\title{
Grapevine Trunk Diseases in British Columbia: Incidence and Characterization of the Fungal Pathogens Associated with Black Foot Disease of Grapevine
}

\author{
J. R. Úrbez-Torres, P. Haag, P. Bowen, and D. T. O'Gorman, Agriculture and Agri-Food Canada, Pacific Agri-Food Research Centre, \\ Summerland, British Columbia V0H 1Z0, Canada
}

\begin{abstract}
Úrbez-Torres, J. R., Haag, P., Bowen, P., and O’Gorman, D. T. 2014. Grapevine trunk diseases in British Columbia: Incidence and characterization of the fungal pathogens associated with black foot disease of grapevine. Plant Dis. 98:456-468.

Black foot disease of grapevines, caused by several fungal species in the genera Campylocarpon, Cylindrocarpon, Cylindrocladiella, and Ilyonectria, causes significant economic losses to the grapevine industry worldwide. This study represents the first attempt to identify and characterize the fungal pathogens associated with black foot disease of grapevines in British Columbia (BC). Field surveys conducted throughout all grape-growing regions in $\mathrm{BC}$ that included assessment of foliar symptomatology and isolations from symptomatic vines showed Cylindrocarpon/Ilyonectria spp. occurred in 32 of $90(35.5 \%)$ young vineyards surveyed ( $\leq 8$ year old) and in 41 of $215(19 \%)$ samples collected. In 20 of the $41(48.8 \%)$ samples, Cylindrocarpon/ Ilyonectria spp. were the sole fungi isolated from symptomatic tissue.

In the rest of the samples, black foot fungi were found to primarily coexist with fungal taxa associated with Petri disease of grapevines. Colony and conidia phenotypical characterization, along with DNA analyses of the internal transcribed spacer region (ITS1-5.8S-ITS2) of the rDNA, and part of the $\beta$-tubulin and translation elongation factor 1$\alpha$ genes, revealed five different black foot fungi occurring in declining young vines in BC, namely Cylindrocarpon pauciseptatum, Ilyonectria liriodendri, Ilyonectria macrodidyma, Ilyonectria robusta, and Ilyonectria torresensis. Pathogenicity studies showed all five species to be highly virulent in the grapevine rootstock cultivar 3309C. Overall, $I$. liriodendri and I. macrodidyma were the most virulent species when inoculated in Vitis vinifera 'Chardonnay’ and rootstock 3309C.
\end{abstract}

Black foot is a grapevine trunk disease that with Petri disease is part of the young vine decline complex (YVD) (16). Black foot disease symptoms were first described in grapevines in France under the name of "gangrene" in the early 1960s (25), and although the disease is long known to occur in grapes, it has become a worsening problem in both nurseries and young commercial vineyards since the early 1990s (16). Black foot primarily affects young grapevines (up to 8 years old), and symptoms of the disease are characterized by sunken necrotic root lesions with a reduction in root biomass and root hairs. Internally, necrotic tissue and plugged xylem vessels with black inclusion and/or tyloses can be observed in cross-section at the basal end of the trunk. Aboveground, vines can either show lack of spring growth or stunted growth characterized by short shoot internodes and small chlorotic leaves, which lead to eventual death of the vines either during the growing season or during the following winter $(5,21,32)$. Since large investments in vineyard establishment and maintenance are needed before full crop and subsequently cash returns are obtained, a long lifespan for vines is essential for economic success in vineyards. Hence, the decline and death of young vines can cause significant economic losses to the grape industry. Black foot disease is now known to occur in all major grape-growing regions including, Europe $(5,35)$, the Near East (28), Oceania $(22,49)$, South Africa (22), and North and South America (1,6,31,32).

Cylindrocarpon destructans (Zinnsm.) Scholten was originally thought to be the main and most widespread causal organism of black foot disease worldwide $(17,32,35)$. However, $C$. destructans isolates from symptomatic grapevines from different continents were revealed to be Cylindrocarpon liriodendri J.D. MacDonald \&

Corresponding author: J. R. Úrbez-Torres,

E-mail: joseramon.urbeztorres@agr.gc.ca

Accepted for publication 30 August 2013.

http://dx.doi.org/10.1094/PDIS-05-13-0524-RE

() 2014 Department of Agriculture and Agri-Food, Government of Canada
E.E. Butler (teleomorph: Ilyonectria liriodendri (Halleen, Rego \& Crous) P. Chaverri \& C. Salgado) based on morphological characters and multi-gene phylogenies $(11,23,34)$. In addition, although Cylindrocarpon obtusisporium (Cooke \& Harkness) Wollenweber was identified as the cause of black foot disease in Italy (18) and California (37), the role that this species plays in the syndrome is still uncertain. Morphological similarities between $C$. obtusisporium and Cylindrocarpon macrodidymum Schroers, Halleen \& Crous (teleomorph: Ilyonectria macrodidyma (Halleen, Schroers \& Crous) P. Chaverri \& C. Salgado) macroconidia along with recent field surveys supported by DNA-based identification methods suggested that $C$. obtusisporium isolates from grapevines were misidentified and were probably $C$. macrodidymum $(22,32)$. Based on recent morphological, molecular, and pathogenicity studies, 18 different fungal species are currently known to be associated with black foot disease of grapevines, including Campylocarpon fasciculare Schroers, Halleen \& Crous, Campylocarpon pseudofasciculare Halleen, Schroers \& Crous, Cylindrocarpon pauciseptatum Schroers \& Crous, Cylindrocladiella parva (P.J. Anderson) Boesewinkel, Cylindrocladiella peruviana (Batista, J.L. Bezerra \& M.P. Herrera) Boesewinkel, Ilyonectria alcacerensis A. Cabral, Oliveira \& Crous, Ilyonectria europaea A. Cabral, Rego \& Crous, Ilyonectria estremocensis A. Cabral, Nascimento \& Crous, I. liriodendri, Ilyonectria lusitanica A. Cabral, Rego \& Crous, I. macrodidyma, Ilyonectria novazelandica A. Cabral \& Crous, Ilyonectria pseudodestructans A. Cabral, Rego \& Crous, Ilyonectria robusta (A.A. Hildebr.) A. Cabral \& Crous, Ilyonectria torresensis A. Cabral, Rego \& Crous, Ilyonectria vitis A. Cabral, Rego \& Crous, and two as yet uncharacterized Ilyonectria species known as Ilyonectria sp. 1 and Ilyonectria sp. 2 (2,8,10,22-24,32,39).

Grapevines (Vitis vinifera L. and Vitis spp.) are the third largest fruit crop in Canada, with 11,784 ha under cultivation and a farm gate value of over $\$ 112.5$ million CAD in 2011 (42). To date, 16 species of Cylindrocarpon Wollenweber have been reported to occur in over 55 hosts in Canada including native and introduced forest tree species as well as economically important annual and perennial crops $(7,12,14,40,41)$. However, the status and impacts of this genus on grapevines has long been overlooked. Seifert and Axelrood (40) first reported one isolate of Cylindrocarpon 
destructans var. destructans from roots and stems of $V$. vinifera in Vineland, Ontario. However, a later phylogenetic study showed this isolate to be misidentified and was renamed Cylindrocarpon sp. (41). A recent field survey conducted by Petit et al. (31) throughout grape-growing regions of northeastern United States and southeastern Canada revealed that Cylindrocarpon didymum (Harting) Wollenweber, I. liriodendri, and I. macrodidyma occur in black foot symptomatic vines in the province of Québec in Canada. Nowadays, no information is available about the status of black foot disease of grapevines in British Columbia (BC), which after Ontario is the second largest grape-growing province in Canada. Consequently, this study was undertaken to determine the occurrence of black foot disease in young vineyards throughout BC and to characterize the different species associated with this disease in the province by means of morphological characters, multi-gene sequencing, and pathogenicity studies.

\section{Materials and Methods}

Field surveys and fungal isolation. To assess the incidence of black foot in BC, 90 young vineyards ( $\leq 8$ years old) were surveyed throughout all grape growing regions of the province, including the Okanagan, the Similkameen, and the Fraser valleys, Vancouver Island, and the Gulf Islands between 2008 and 2012. In total, 215 samples (entire or portions of a plant) were collected and brought to the laboratory to identify the different black foot fungi occurring in symptomatic vascular tissue from grapevines showing characteristic decline in the field. Grapevine samples were first surfacesterilized by submerging them in $4.5 \%$ sodium hypochlorite for 5 min and washed twice with sterile distilled water. After air-drying, sampled vines were inspected for presence of necrotic roots, and if detected, fungi from roots were isolated as described by Petit and Gubler (32). Additionally, samples were sectioned to reveal the vascular symptoms in the trunk, and fungi associated with symptomatic tissue were isolated as described by Úrbez-Torres et al. (45). Small pieces of symptomatic tissues from trunk or roots were incubated on potato dextrose agar (PDA) (Difco, Detroit, MI) plates amended with tetracycline hydrochloride $(0.01 \%)$ (SigmaAldrich, St Louis, MO) (PDA-tet) at $20^{\circ} \mathrm{C}$ in the dark until fungal colonies were observed. Colonies were individually transferred to fresh PDA. Afterwards, pure cultures were obtained by hyphaltipping from colony margins and by placing them again on fresh PDA plates at $20^{\circ} \mathrm{C}$ in the dark. Pure culture colonies were used to conduct a preliminary morphological identification of the different fungi isolated from symptomatic grapevine tissue.

Morphological characterization. Among all the different fungi isolated from symptomatic tissue, Cylindrocarpon-like species were first tentatively classified in different groups based on previously described macroscopic and microscopic characters of the colony (color, texture, and type of growing margin) and conidia (shape and number of septa), respectively $(5,22,32)$. Pure cultures from representative isolates of each group were selected to measure the length and width of each type of conidium observed (microconidia and one- to five-septa macroconidia) including chlamydospores if present (Table 1). Small colonized agar plugs (approximately $9 \mathrm{~mm}^{2}$ ) were removed from 15-day-old pure culture colony margins and examined microscopically. Pictures of the different conidia present in each selected sample were taken at $\times 40$ magnification using a Zeiss Axiophot compound microscope with DIC optics and captured using a Nikon D700 digital camera. The length and width of at least 10 conidia per type per isolate were measured using the Image-Pro Plus software (v4.5.1.29, Media Cybernetics, Inc.). For each type of conidium: minimum, lower limit of a $95 \%$ interval; mean, upper limit of a $95 \%$ interval; and maximum were calculated for both length and width measurements using summary statistics in SAS (v9.3, SAS Institute, Cary, NC). Additionally, macroscopic and microscopic morphological characteristics were compared with reference isolates including ex-type specimens obtained from the Centraalbureau voor Schimmelcultures (CBS) collection in Utrecht, the Netherlands (Table 2).

Molecular characterization and multi-gene analysis. Fungal isolates selected for DNA extraction were cultured on PDA and grown to a 3- to 4-cm-diameter colony (Table 1). Total genomic DNA was extracted using the PowerSoil DNA Isolation Kit (MO BIO Laboratories Inc., Carlsbad, CA). Oligonucleotide primers ITS1 and ITS4, Bt2a and Bt2b, and EF1 and EF2 were used to amplify the ITS1-5.8S-ITS2 gene (ITS), a portion of the $\beta$-tubulin (BT), and part of the translation elongation factor $1-\alpha(E F 1-\alpha)$

Table 1. Cylindrocarpon and Ilyonectria species isolated from Vitis vinifera in British Columbia used in this study

\begin{tabular}{|c|c|c|c|c|c|c|}
\hline \multirow[b]{2}{*}{ Species } & \multirow[b]{2}{*}{ Isolate $^{\mathbf{b}}$} & \multirow[b]{2}{*}{ Cultivar $^{c}$} & \multirow[b]{2}{*}{ Collector } & \multicolumn{3}{|c|}{ GenBank accession numbers ${ }^{a}$} \\
\hline & & & & ITS & BT & EF1- $\alpha$ \\
\hline C. pauciseptatum & $\begin{array}{l}\text { PARC } 82 * \\
\text { DAOM } 242314\end{array}$ & $\mathrm{SO} 4$ & P. Haag \& D.T. O'Gorman & KF511996 & KF511968 & KF511981 \\
\hline C. pauciseptatum & $\begin{array}{l}\text { PARC } 407 \\
\text { DAOM } 242315\end{array}$ & $3309 \mathrm{C}$ & J.R. Úrbez-Torres & KF511997 & KF511969 & KF511982 \\
\hline I. liriodendri & PARC60 & Chardonnay ${ }^{\mathrm{d}}$ & P. Haag \& D.T. O’Gorman & KF511998 & KF511970 & KF511983 \\
\hline I. liriodendri & $\begin{array}{l}\text { PARC72* } \\
\text { DAOM } 242317\end{array}$ & Pinot Gris ${ }^{\mathrm{d}}$ & P. Haag \& D.T. O'Gorman & KF511999 & KF511971 & KF511984 \\
\hline I. liriodendri & $\begin{array}{l}\text { PARC } 340^{*} \\
\text { DAOM } 242318\end{array}$ & $3309 \mathrm{C}$ & J.R. Úrbez-Torres & KF512000 & KF511972 & KF511985 \\
\hline I. liriodendri & PARC393 & $\mathrm{SO} 4$ & J.R. Úrbez-Torres & KF512001 & KF511973 & KF511986 \\
\hline I. macrodidyma & $\begin{array}{l}\text { PARC } 345^{*} \\
\text { DAOM } 242320\end{array}$ & $3309 \mathrm{C}$ & J.R. Úrbez-Torres & KF512002 & KF511974 & KF511989 \\
\hline I. macrodidyma & $\begin{array}{l}\text { PARC } 398^{*} \\
\text { DAOM } 242321\end{array}$ & $3309 \mathrm{C}$ & J.R. Úrbez-Torres & KF512003 & KF511975 & KF511990 \\
\hline I. robusta & $\begin{array}{l}\text { PARC } 358^{*} \\
\text { DAOM } 242322\end{array}$ & Pinot Gris ${ }^{\mathrm{d}}$ & J.R. Úrbez-Torres & KF512004 & KF511976 & KF511991 \\
\hline I. robusta & $\begin{array}{l}\text { PARC } 391 * \\
\text { DAOM } 242323\end{array}$ & $3309 \mathrm{C}$ & J.R. Úrbez-Torres & KF512005 & KF511977 & KF511992 \\
\hline I. torresensis & $\begin{array}{l}\text { PARC14* } \\
\text { DAOM } 242324\end{array}$ & $3309 \mathrm{C}$ & P. Haag \& D.T. O'Gorman & KF512006 & KF511978 & KF511993 \\
\hline I. torresensis & $\begin{array}{l}\text { PARC } 35^{*} \\
\text { DAOM } 242325\end{array}$ & $3309 \mathrm{C}$ & P. Haag \& D.T. O'Gorman & KF512007 & KF511979 & KF511994 \\
\hline I. torresensis & PARC142 & $3309 \mathrm{C}$ & J.R. Úrbez-Torres & KF512008 & KF511980 & KF511995 \\
\hline
\end{tabular}

${ }^{a}$ ITS: internal transcribed spacer. BT: $\beta$-tubulin. EF1- $\alpha$ : translation elongation factor $1-\alpha$.

b PARC: Pacific Agri-Food Research Centre. DAOM: Department of Agriculture Ottawa Mycology. Isolates used in the pathogenicity studies are indicated with an asterisk.

${ }^{\mathrm{c}}$ Grapevine (pure Vitis vinifera or rootstock) material from which the fungus was isolated.

d Self-rooted. 
gene, respectively $(15,29,48)$. Each polymerase chain reaction (PCR) contained $2 \mu \mathrm{l}$ of $10 \times$ PCR buffer containing $15 \mathrm{mM} \mathrm{MgCl}_{2}$, $1.6 \mu \mathrm{l}$ of $25 \mathrm{mM} \mathrm{MgCl} 2,1 \mu \mathrm{l}$ of $10 \mathrm{mM}$ dNTPs, $0.5 \mu \mathrm{l}$ of $0.5 \mathrm{mM}$ of each primer, $0.1 \mu \mathrm{l}$ of Ultra Therm DNA polymerase (BocaScientific, Boca Raton, FL), and $1 \mu \mathrm{l}$ of DNA template adjusted with micropore filtered water to a final volume of $20 \mu \mathrm{l}$. ITS, BT, and EF1- $\alpha$ amplification reactions were carried out on a GeneAmp 2700 thermal cycler (Applied Biosystems, Foster City, CA) following previously described ITS (48), BT (15), and EF1- $\alpha$ (29) temperature profiles. Amplification products were purified using a QIAquick PCR purification Kit (QIAGEN Inc., Valencia, CA). Both strands of the ITS, BT, and EF1- $\alpha$ were sequenced using a 48-capillary 3730 DNA Analyzer (Applied Biosystems) in the NAPS Unit at the Michael Smith Laboratories, University of
British Columbia, Vancouver. Sequences were edited and assembled using Lasergene SeqMan Pro version 9.1.1.4 (DNASTAR Inc., Madison, WI). Consensus sequences were then compared with those available in the GenBank database by using the Basic Local Alignment Search Tool (BLAST) to verify the preliminary morphological identification and select closely related sequences for the multi-locus phylogenetic analyses.

Fungal sequences from grapevines from $\mathrm{BC}$ were aligned with published GenBank sequences, including ex-type specimens from grapevines and other hosts for comparison using the computer software BioEdit Sequence Alignment Editor Version 7.1.3.0 (19) (Table 2). Alignments were corrected visually and manually edited. Single phylogenetic analyses for each loci data set were conducted using Maximum Parsimony (MP) and the heuristic search option

Table 2. Fungal species used for morphological comparison and phylogenetic analyses

\begin{tabular}{|c|c|c|c|c|c|c|}
\hline \multirow[b]{2}{*}{ Species } & \multirow[b]{2}{*}{ Isolate $^{b}$} & \multirow[b]{2}{*}{ Host / Origin } & \multirow[b]{2}{*}{ Collector } & \multicolumn{3}{|c|}{ GenBank accession numbers $^{\mathrm{a}}$} \\
\hline & & & & ITS & BT & EF1- $\alpha$ \\
\hline Campylocarpon fasciculare & CBS $112613^{c}$ & Vitis vinifera / South Africa & F. Halleen & AY677301 & AY677221 & JF735691 \\
\hline $\begin{array}{l}\text { Campylocarpon } \\
\text { pseudofasciculare }\end{array}$ & CBS $112679 c$ & V. vinifera / South Africa & F. Halleen & AY677306 & AY677214 & JF735692 \\
\hline Cylindrocarpon cylindroides & CBS 503.67 ${ }^{\mathrm{c}}$ & Abies alba / Norway & F. Roll-Hansen & AY677261 & JF735436 & JF735789 \\
\hline Cylindrocarpon obtusisporium & CBS $183.36^{c}$ & Solanum tuberosum / Germany & H.W. Wollenweber & AM419061 & AM419085 & JF735796 \\
\hline C. obtusisporium & СРC 13544 & Prunus armeniaca / Canada & J.A. Traquair & AY295306 & JF735443 & JF735797 \\
\hline Cylindrocarpon pauciseptatum & CBS 120171 ${ }^{\mathrm{c}}$ & Vitis sp. / Slovenia & M. Žerjav & EF607089 & EF607066 & JF735776 \\
\hline C. pauciseptatum & CBS 120498 & Vitis sp. / Slovenia & M. Žerjav & EF607087 & EF607072 & JF735774 \\
\hline C. pauciseptatum & CBS 100819 & Erica melanthera / New Zealand & H.M. Dance & EF607090 & EF607067 & JF735771 \\
\hline Cylindrocarpon theobromicola & CBS 218.67c & $\begin{array}{l}\text { Theobroma cacao / Papua New } \\
\text { Guinea }\end{array}$ & P.G. Hicks & EF607092 & EF607062 & KF511967 \\
\hline Ilyonectria alacerensis & CBS 129087 & V. vinifera / Portugal & $\begin{array}{l}\text { A. Cabral \& } \\
\text { H. Oliveira }\end{array}$ & JF735333 & AM419111 & JF735819 \\
\hline Ilyonectria anthuriicola & CBS 564.95 & Anthurium sp. / Netherlands & R. Pieters & JF735302 & JF735430 & JF735768 \\
\hline Ilyonectria coprosmae & CBS 119606 & Metrosideros sp. / Canada & G.J. Samuels & JF735260 & JF735373 & JF735694 \\
\hline Ilyonectria cyclaminicola & CBS 302.93 & Cyclamen sp. / Netherlands & M. Hooftman & JF735304 & JF735432 & JF735770 \\
\hline Ilyonectria estremocensis & CBS 129085 & V. vinifera / Portugal & $\begin{array}{l}\text { C. Rego \& } \\
\text { T. Nascimento }\end{array}$ & JF735320 & JF735448 & JF735806 \\
\hline Ilyonectria europaea & CBS 129078 & V. vinifera / Portugal & C. Rego & JF735294 & JF735421 & JF735756 \\
\hline Ilyonectria gamsii & CBS 940.97 ${ }^{\mathrm{c}}$ & Soil / Netherlands & J.T. Poll & AM419065 & AM419089 & JF735766 \\
\hline Ilyonectria liliigena & CBS 189.49 & Lilium regale / Netherlands & M.A.A. Schipper & JF735297 & JF735425 & JF735762 \\
\hline Ilyonectria liriodendri & CBS $110.81^{c}$ & $\begin{array}{l}\text { Liriodendron tulipifera / USA, } \\
\text { CA }\end{array}$ & $\begin{array}{l}\text { J.D. MacDonald \& } \\
\text { E.E. Butler }\end{array}$ & DQ178163 & DQ178170 & JF735696 \\
\hline I. liriodendri & CBS $112595^{\mathrm{c}}$ & V. vinifera / South Africa & F. Halleen & AY677263 & AY677247 & KF511987 \\
\hline I. liriodendri & CBS $112599^{c}$ & V. vinifera / France & $\mathrm{n} / \mathrm{a}$ & AY677266 & AY677243 & KF511989 \\
\hline Ilyonectria lusitanica & CBS 129080 & V. vinifera / Portugal & N. Cruz & JF735296 & JF735423 & JF735759 \\
\hline Ilyonectria macrodidyma & CBS $112615^{\mathrm{c}}$ & V. vinifera / South Africa & F. Halleen & AY677290 & AY677233 & JF735836 \\
\hline I. macrodidyma & CBS 112594 & V. vinifera / South Africa & F. Halleen & AY677282 & AY677231 & JF735832 \\
\hline I. macrodidyma & Cy140 & V. vinifera / Portugal & $\begin{array}{l}\text { C. Rego \& } \\
\text { T. Nascimento }\end{array}$ & JF735343 & JF735472 & JF735840 \\
\hline Ilyonectria mors-panacis & CBS 306.35 & Panax quinquefolium / Canada & A.A. Hildebrand & JF735288 & JF735414 & JF735746 \\
\hline Ilyonectria novozelandica & CBS 113552 & Vitis sp. / New Zealand & B. Bonfiglioli & JF735334 & AY677237 & JF735822 \\
\hline I. novozelandica & Cy116 & Vitis vinifera / USA, CA & W.D. Gubler & AJ875322 & JF735461 & JF735824 \\
\hline Ilyonectria panacis & CBS 129079 & P. quinquefolium / Canada & K.F. Chang & AY295316 & JF735424 & JF735761 \\
\hline Ilyonectria pseudodestructans & CBS 129081 & V. vinifera / Portugal & C. Rego & AJ875330 & AM419091 & JF735752 \\
\hline Ilyonectria radicicola & CBS 264.65 & Cyclamen persicum / Sweden & L. Nilsson & AY677273 & AY677256 & JF735695 \\
\hline Ilyonectria robusta & CBS 308.35 & P. quinquefolium / Canada & A.A. Hildebrand & JF735264 & JF735377 & JF735707 \\
\hline I. robusta & CBS $773.83^{\mathrm{c}}$ & Water in aquarium / Netherlands & J. Hemelraad & AY677276 & AY677254 & JF735708 \\
\hline Ilyonectria rufa & CBS 153.37 & Dune sand / France & F. Moreau & AY677271 & AY677251 & JF735729 \\
\hline Ilyonectria sp. 1 & CBS 162.89 & Hordeum vulgare / Netherlands & M. Barth & AM419060 & AM419084 & JF735799 \\
\hline Ilyonectria sp. 2 & CBS 173.37 & Pinus laricio / England & T.R. Peace & JF735319 & JF735447 & JF735803 \\
\hline Ilyonectria torresensis & CBS 129086 & V. vinifera / Portugal & A. Cabral & JF735362 & JF735492 & JF735870 \\
\hline I. torresensis & CBS 112609 & Vitis sp. / Australia & M. Sweetingham & AY677289 & AY677226 & JF735849 \\
\hline I. torresensis & СРC 13533 & V. vinifera / Canada & H.F. Dias & AY295332 & JF735480 & JF735852 \\
\hline Ilyonectria venezuelensis & CBS 102032 & Bark / Venezuela & A. Rossman & AM419059 & AY677255 & JF735760 \\
\hline Ilyonectria vitis & CBS 129082 & V. vinifera / Portugal & C. Rego & JF735303 & JF735431 & JF735769 \\
\hline Neonectria ditissima & CBS 226.31 & Fagus sylvatica / Germany & H.W. Wollenweber & JF735309 & DQ789869 & JF735783 \\
\hline Neonectria faginata & CBS 217.67 ${ }^{c}$ & Fagus grandifolia / Canada & G.L. Stone & HQ840385 & JF268730 & JF268746 \\
\hline Neonectria macroconidialis & CBS 119596 & Astelia sp. / New Zealand & G.J. Samuels & JF735259 & JF735372 & JF735693 \\
\hline Neonectria major & CBS 240.29 & Alnus incana / Norway & H.W. Wollenweber & JF735308 & DQ789872 & JF735782 \\
\hline Neonectria neomacrospora & CBS 118984 & Arceuthobium tsugense / Canada & L. Reitman & JF735311 & DQ789882 & JF735787 \\
\hline Neonectria ramulariae & CBS 151.29 & Malus sylvestris / England & H.W. Wollenweber & JF735314 & JF735439 & JF735792 \\
\hline Neonectria veullotiana & NZFS3602 & Pinus radiate / New Zealand & $\mathrm{n} / \mathrm{a}$ & JQ013490 & JQ013500 & JQ013501 \\
\hline
\end{tabular}


with 1,000 random additional sequence replicates with CloseNeighbor-Interchange (CNI) algorithm in MEGA5 (43), and tree topologies were compared (individual trees not shown). A multilocus phylogenetic analysis was performed on the combined ITS, BT, and EF1- $\alpha$ datasets using MP as previously described. Tree length, consistency index (CI), retention index (RI), and rescaled consistency index (RC) were calculated. The combined ITS, BT, and EF1- $\alpha$ datasets were further analyzed by Neighbor-Joining (NJ) using the Maximum Composite Likelihood method. Bootstrap support was estimated using 1,000 replicates to assess the robustness of each clade in both MP and NJ phylogenetic methods. Sequences from fungal isolates collected in this study were deposited into GenBank, and representative isolates are maintained in the grapevine trunk disease fungal collection at the Pacific AgriFood Research Centre in Summerland, BC, and in the Canadian Collection of Fungal Cultures in Ottawa, Ontario (Table 1).

Pathogenicity studies. Isolates representing the five different species identified from symptomatic wood tissue were selected to determine their pathogenicity in 'Chardonnay' and 3309C rootstock cultivars (Table 1). Nine isolates for Chardonnay and eight for 3309C rootstock were used. In the first experiment, dormant canes of Chardonnay were collected from an experimental vineyard located at the Pacific Agri-Food Research Centre in Summerland in mid-March of 2012. Six canes per fungal isolate were inoculated using 10-day-old mycelium plugs as described by Úrbez-Torres et al. (45). Twelve additional canes were inoculated with noncolonized PDA plugs for negative controls. Inoculated canes were immediately placed on a metal rack in 6 liter transparent plastic containers with a tight-fitting lid containing $400 \mathrm{ml}$ of distilled water to maintain a humid environment. Treatments were arranged in a completely randomized design with 12 canes per container. Inoculated canes were collected after 31 days of incubation at room temperature and inspected for lesion development. Each cane was sectioned longitudinally through the point of inoculation, and the extent of vascular discoloration was measured upward and downward from the point of inoculation using a digital caliper (Mitutoyo Corporation, Tokyo, Japan). Ten small pieces (approximately $9 \mathrm{~mm}^{2}$ ) of necrotic tissue from the edge of each lesion were cut and placed on PDA-tet in an attempt to recover the inoculated fungus and complete Koch's postulates. Fungal identity was verified based on colony and conidial morphology.

The second pathogenicity experiment was conducted in 1-yearold dormant rooted vines of 'Baco Noir' grafted on 3309C rootstock. Inoculum from each isolate was prepared as described by Alaniz et al. (5), and conidial concentration was adjusted with a hemacytometer to $10^{6}$ conidia per $\mathrm{ml}$. Before inoculation, roots were trimmed and disinfested by immersion for $5 \mathrm{~min}$ in a $4.5 \%$ sodium hypochlorite solution. After air-drying, six vines per fungal isolate were inoculated by immersing the roots and the basal end of the trunk in the spore solution overnight. Twelve control plants were immersed in sterile water. After inoculation, rooted vines were planted in 4-liter pots containing a standard potting soil mixture. Plants were maintained in a greenhouse $\left(27 \pm 5^{\circ} \mathrm{C}, 30\right.$ to $40 \%$ relative humidity) in a completely randomized design and watered as needed. Twenty-one weeks after inoculation, growth characteristics of the grapevines, including total shoot length, average internode length, total pruning weight, length of the longest root, and dry root weight, were compared to the control plants (9). Additionally, roots and the basal end of the rootstock of each plant were inspected for necrosis and vascular discoloration, respectively. Both roots and the basal end of the rootstock were first disinfested as previously described. After air-drying, 10 small pieces of necrotic tissue from two different roots ( 5 pieces each) were placed on PDA-tet in an attempt to recover the inoculated fungus and complete Koch's postulates. Subsequently, the rootstock was sectioned transversely at the basal end. Transversal sections were scanned and the total necrotic area was calculated using the Fiji image processing computer program (38). Rootstocks were then sectioned longitudinally, and the extent of vascular discoloration was measured from the basal end using a digital caliper. Ten small pieces of necrotic tissue from the edge of each lesion were cut and placed on PDA-tet in an attempt to recover the inoculated fungus and complete Koch's postulates.

Data from both pathogenicity studies and grapevine growth parameters were independently analyzed by one-way analysis of variance (ANOVA) conducted using the SAS GLM Procedure. Homogeneity of variance was tested using Levene's test. Residuals were visually inspected for each treatment, and when necessary a $\log _{10}$ transformation was used to improve homogeneity of variance. Treatment means were compared using Tukey's test at the 5\% significant level.

\section{Results}

Incidence of black foot disease of grapevines in BC. Characteristic symptoms of declining young vines were observed in 68 of the 90 young vineyards surveyed $(75.5 \%)$ and affected all grapegrowing regions in BC. During the early part of the growing season (April to June), symptomatic young vines were stunted and characterized by short shoot internodes and chlorotic leaves in either the entire vine or part of it (Fig. 1A and B). Within each vineyard, symptomatic vines appeared to be distributed either as several single vines randomly located throughout the vineyard (Fig. 1A) or as a group of vines located in a specific area of the vineyard (Fig. 1C). Throughout the growing season (July to September), shoots of some of the symptomatic vines progressively dried out beginning with the leaves which consequently dropped and then the clusters which shriveled (Fig. 1D). This vine collapse was observed to affect the entire vine, a single cordon, or just one or more spur positions in a cordon. Vascular symptoms were primarily characterized by dark streaking of the wood in the trunk, especially developing from the basal end (Fig. 1E). Cross-sections of the basal end of symptomatic trunks revealed a necrotic area around the pith, which in some cases was characterized by the presence of tyloses plugging the xylem vessels (Fig. 1F). Depending on the level of infection, the necrotic area extended just 1 to $2 \mathrm{~mm}$ from the pith or had affected the entire section of the trunk (Fig. 1G). Additionally, wedge-shape necrotic lesions were occasionally observed in thick mature roots and extending into the basal end of the trunk (Fig. 1H). Many symptomatic vines had sunken necrotic roots, which in some cases were associated with the syndrome known as "J-root" (Fig. 1I). Fungal species associated with black foot disease occurred in 32 of $90(35.5 \%)$ young vineyards surveyed and were isolated from 41 of $215(19 \%)$ samples collected (Table 3). In 20 of the 41 (48.8\%) samples, Cylindrocarpon/ Ilyonectria spp. were the sole fungi isolated from symptomatic tissue (Table 3). In the rest of the samples, black foot fungi were found to primarily coexist with fungal taxa associated wth Petri disease of grapevines and to a lesser extent with other grapevine trunk disease pathogens in the Botryosphaeriaceae family and the Diaporthe/Phomopsis genera (Table 3). Although black foot disease pathogens were isolated from necrotic roots observed in vines characterized by either poor or no spring growth, the majority of Ilyonectria/Cylindrocarpon spp. in this study were isolated from the necrotic tissue observed at the basal end of the trunk (rootstock or self-rooted cultivar) (Table 3).

Morphological characterization. Cylindrocarpon-like colonies developing from symptomatic tissue were first identified by the characteristic saffron and/or buff colony color on PDA $(10,23,32)$ (Fig. 2A). Both micro- and macroconidia were produced by all isolates on PDA, and measurements from each type of conidium from each species including the ex-type specimens are given in Table 4. Colony and conidia morphology allowed us to separate all isolates in five different morphological groups by comparison to reference isolates from CBS and previously published data $(10,23,32)$.

The first group included five isolates and was first characterized by a light cream, raised mycelium with slightly lobulated colony margins. With age, the colonies became yellowish to goldenyellow in the center (Fig. 2B). Colony growth on PDA averaged 

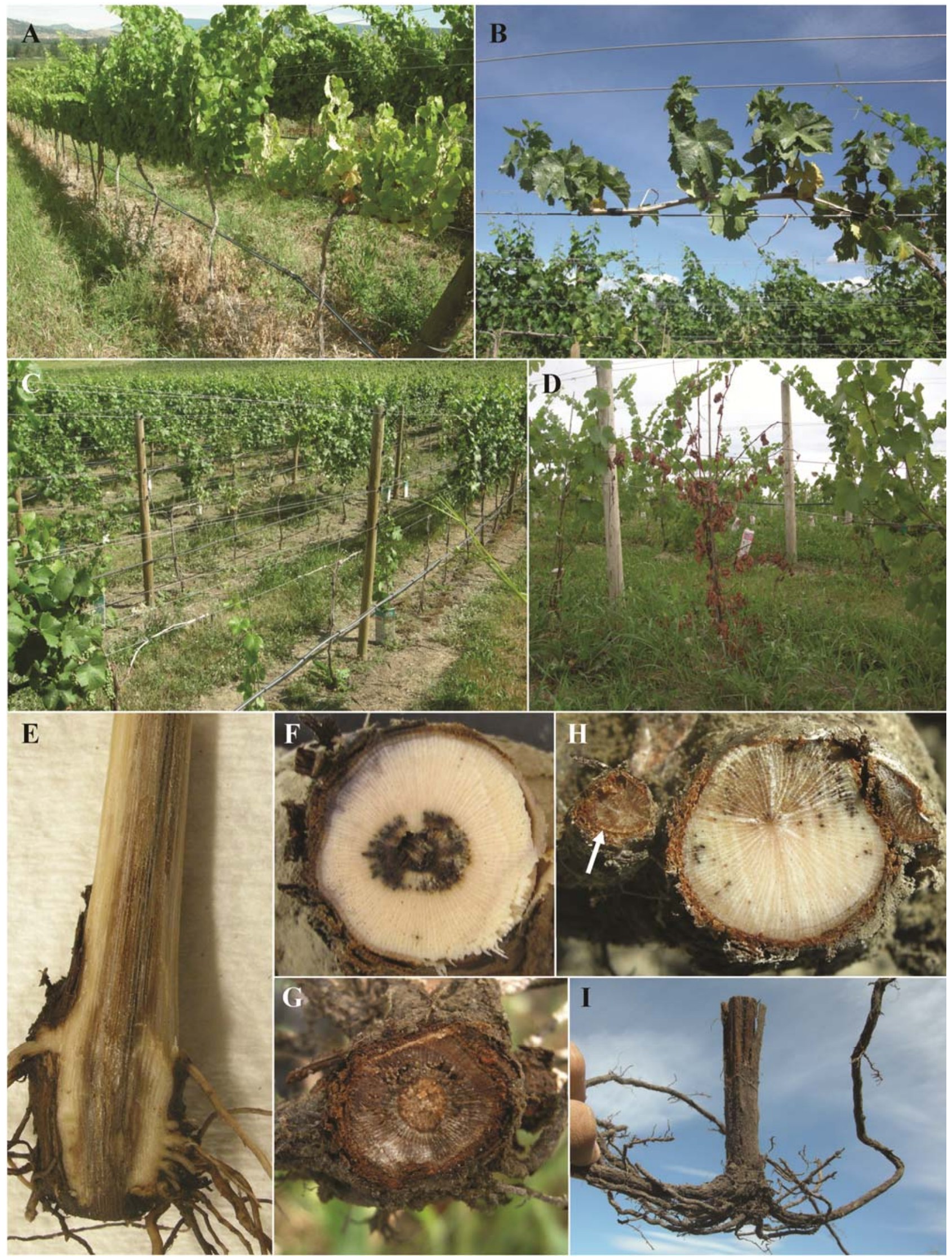

Fig. 1. Young vine decline symptoms observed in British Columbia. A and B, Stunted growth observed in late spring and characterized by chlorotic leaves and short shoot internodes. C, Declining of young vines affecting a significant part of the vineyard. D, Vine collapse observed during the growing season and characterized by leaf drop and shriveling of clusters. E, Dark-brown to black streaking of the wood could be observed in young vines developing from the basal end of the trunk. F, Cross sections at the basal end of the trunk revealed vascular necrosis around the pith. G, Fungi were observed to colonize the entire section of the trunk. H, Cross section of roots from symptomatic plants revealed total rot necrosis (white arrow) and/or wedge-shaped necrosis. I, "J-root" syndrome was observed to be associated with many declining young vines. 
$72 \mathrm{~mm}$ diameter after 17 days at $20^{\circ} \mathrm{C}$. Morphological characteristics of micro- and macroconidia (Fig. 2G), the latter having predominantly three septa, were consistent with the description of $C$. pauciseptatum (39). Macroconidia of $C$. pauciseptatum isolates from $\mathrm{BC}$ were slightly longer than those recorded from the ex-type specimen CBS 120171 (Table 4). The second group included 20 isolates and was characterized by a light to dark brown, flat mycelium, with slightly lobulated light orange colony margin (Fig. 2C). Its colony growth on PDA averaged 78 $\mathrm{mm}$ diameter after 17 days at $20^{\circ} \mathrm{C}$. Dimensions and morphology of micro- and macroconidia (Fig. 2H), the latter having predominantly one-septum, were in concordance with the $I$. liriodendri published description (23) and the ex-type specimen CBS 110.81 (Table 4). Isolates within this group developed globose to subglobose chlamydospores $(8.9-18.8 \times 9.7-15.7 \mu \mathrm{m})(n$ $=45$ ) formed singly or in chains (Fig. 2I). The third group included 11 isolates and was characterized by a yellowish, felty mycelium, with an even amber-yellow colony margin (Fig. 2D). Colony growth on PDA averaged $47 \mathrm{~mm}$ diameter after 17 days at $20^{\circ} \mathrm{C}$. Reverse colony was characterized by a strong orange-dark brown color. Colony morphology was in concordance with previous descriptions of I. macrodidyma (5,32). Macroconidia were predominantly three septate, but four and five septa were also observed (Fig. 2J). Length of micro- and macroconidia were longer than those recorded from the I. macrodidyma ex-type specimen CBS 112615, which only had one- and two-septate macroconidia (Table 4). The fourth group included two isolates and was characterized by a light- to dark-brown, flat mycelium, with an even dark orange colony margin (Fig. 2E). Its colony growth was the fastest among all groups, covering the $85 \mathrm{~mm}$ diameter petri plate after 17 days. Macroconidia had predominantly one-septum but two and three septa were also observed (Fig. 2K). Colony morphology and macroconidial shape resemble those described for I. robusta (8). However, length of macroconidia from $\mathrm{BC}$ isolate PARC358 was longer than those recorded from the I. robusta reference isolate CBS 773.83, which only had one- and two-septate macroconidia (Table 3). The last morphological group included three isolates and was characterized by a yellowish, raised mycelium with a pronounced lobulated uneven sepia color colony margin. Isolates from this group had the slowest growth on PDA, reaching only $32 \mathrm{~mm}$ diameter after 17 days at $20^{\circ} \mathrm{C}$ (Fig. $2 \mathrm{~F}$ ). Dimensions and morphology of micro- and macroconidia (Fig. $2 \mathrm{~L}$ ), the latter having predominantly one septum, resembled those described for I. macrodidyma. Isolates within this group were first classified as Cylindrocarpon sp. and were identified to species based on DNA sequence analyses.

Molecular characterization and multi-gene analysis. PCR amplifications of selected regions of ITS, BT, and EF1- $\alpha$ gave products of approximately 500, 400, and $800 \mathrm{bp}$, respectively. To evaluate the phylogenetic relationships among the different Cylindrocarpon/Ilyonectria isolates obtained from grapevines in $\mathrm{BC}$, their ITS, BT, and EF1- $\alpha$ sequences were analyzed by BLAST to confirm the preliminary morphological identification; to identify isolates from the unidentified morphological group five to species and to select closely related sequences for the multi-locus phylogenetic analyses (Table 2). Sixty taxa were included in the phylogenetic analysis of the combined ITS, BT, and EF1- $\alpha$ dataset using MP and NJ. The alignment contained 1,923 characters including gaps. The MP evolutionary history generated 33 equally parsimonious trees, of which one is shown in Figure 3. The NJ analysis resulted in a tree with similar topology as the MP tree. The black foot isolates from BC grapevines separated into five different groups based on morphological characteristics, grouped in five different corresponding clades based on the phylogenetic analysis of the combined ITS, BT, and EF1- $\alpha$ dataset. The first clade, with bootstrap values of $90 \%(\mathrm{MP})$ and $87 \%(\mathrm{NJ})$ consisted of $I$. robusta isolates from BC, which had nearly identical sequences to those of the I. robusta ex-type specimen CBS 308.35 from ginseng (Panax quinquefolium L.) from Canada (Fig. 3). The second clade, with bootstrap values of $99 \%(\mathrm{MP})$ and $100 \%(\mathrm{NJ})$ grouped I. liriodendri isolates from BC with I. liriodendri ex-type specimen CBS 110.81 from tulip tree (Liriodendron tulipifera L.) from California and with reference isolates CBS 112595 and CBS 112599 from grapevines from South Africa (Fig. 3). The third clade, with bootstrap values of $99 \%$ (MP) and $100 \%$ (NJ) included C. pauciseptatum isolates from $\mathrm{BC}$, which grouped together with C. pauciseptatum isolates from Vitis sp. from Slovenia including the ex-type specimen CBS 120171 and with one isolate from ruby shepherd (Erica melanthera L.) from New Zealand. The last clade, with bootstrap values of $70 \%$ (MP) and $80 \%$ (NJ) was formed by two different subclades with bootstrap values lower than $50 \%$, which included $\mathrm{BC}$ isolates from morphological groups three and five, preliminarily identified as I. macrodidyma and Cylindrocarpon sp., respectively (Fig. 3). Within these two subclades, I. macrodidyma isolates from $\mathrm{BC}$ grouped together with I. macrodidyma isolates from grapevines from South Africa and Portugal including the ex-type specimen CBS 112615 (Fig. 3); and I. torresensis isolates from $\mathrm{BC}$, which could not be identified to species based on morphological characters, grouped together with I. torresensis isolates from grapevines from Australia, Canada, and Portugal, including the ex-type specimen CBS 129086 (Fig. 3).

Pathogenicity studies. The extent of vascular discoloration caused by inoculating the fungal isolates on detached Chardonnay dormant canes averaged between 11 and $5.6 \mathrm{~mm} 31$ days after inoculation and were significantly larger $(P<0.0001)$ than those of controls treated with noncolonized agar plugs $(2.1 \mathrm{~mm})$ (Fig. $4 \mathrm{~A}$ and $\mathrm{J}$ ). In this experiment, I. macrodidyma isolates PARC345 and PARC398 caused the longest lesions among all inoculated fungal species (Fig. 4A). Percent recovery was higher than $90 \%$ for all isolates, and fungi obtained from the reisolations were the same as those previously inoculated based on colony and conidia morphology (Fig. 4C). No Cylindrocarpon/Ilyonectria sp. was isolated from the controls.

Twenty-one weeks after inoculation, all Baco Noir vines grafted on 3309C rootstock and inoculated with either Ilyonectria or Cylindrocarpon spp. showed chlorotic leaves with a characteristic scorching at the edge (Fig. 4K). In several of the inoculated plants, a substantial reduction in vigor, characterized by poor shoot

Table 3. Total number of samples yielding black foot fungal species from grapevine vascular symptoms in young vineyards surveyed in British Columbia

\begin{tabular}{|c|c|c|c|c|}
\hline \multirow[b]{2}{*}{ Species isolated } & \multirow[b]{2}{*}{ No. of samples } & \multicolumn{3}{|c|}{ Isolated from } \\
\hline & & Trunk $^{\mathbf{a}}$ & Roots & Trunk $^{c}+$ roots \\
\hline Cylindrocarpon sp. & 20 & 14 & 2 & 4 \\
\hline Cylindrocarpon $\mathrm{sp} .+$ Petri disease pathogen ${ }^{\mathrm{b}}$ & 13 & 10 & 0 & 3 \\
\hline Cylindrocarpon sp. + Petri disease pathogen ${ }^{\mathrm{b}}+$ other $^{\mathrm{c}}$ & 4 & 3 & 0 & 1 \\
\hline Cylindrocarpon $\mathrm{sp} .+$ other $^{\mathrm{c}}$ & 4 & 2 & 0 & 2 \\
\hline Total number of samples yielding black foot fungi & 41 & & & \\
\hline Total number of samples collected & 215 & & & \\
\hline
\end{tabular}


growth, was observed when compared with the controls. Internal necrosis developing acropetally at the basal end of the 3309C rootstock was observed in all inoculated plants (Fig. 4M and N). The extent of vascular discoloration measured from the basal end averaged between 57.5 and $41.7 \mathrm{~mm}$ and was larger $(P<0.0001)$ than that of the water-treated controls $(4.3 \mathrm{~mm})$ (Fig. 4B). In this experiment, I. liriodendri isolate PARC70 caused the longest lesion among all inoculated species (Fig. 4B). Percent recovery from the edge of the necrotic lesion varied between 53.3 and $65 \%$ (Fig. 4C). Necrotic roots were also observed in all inoculated vines
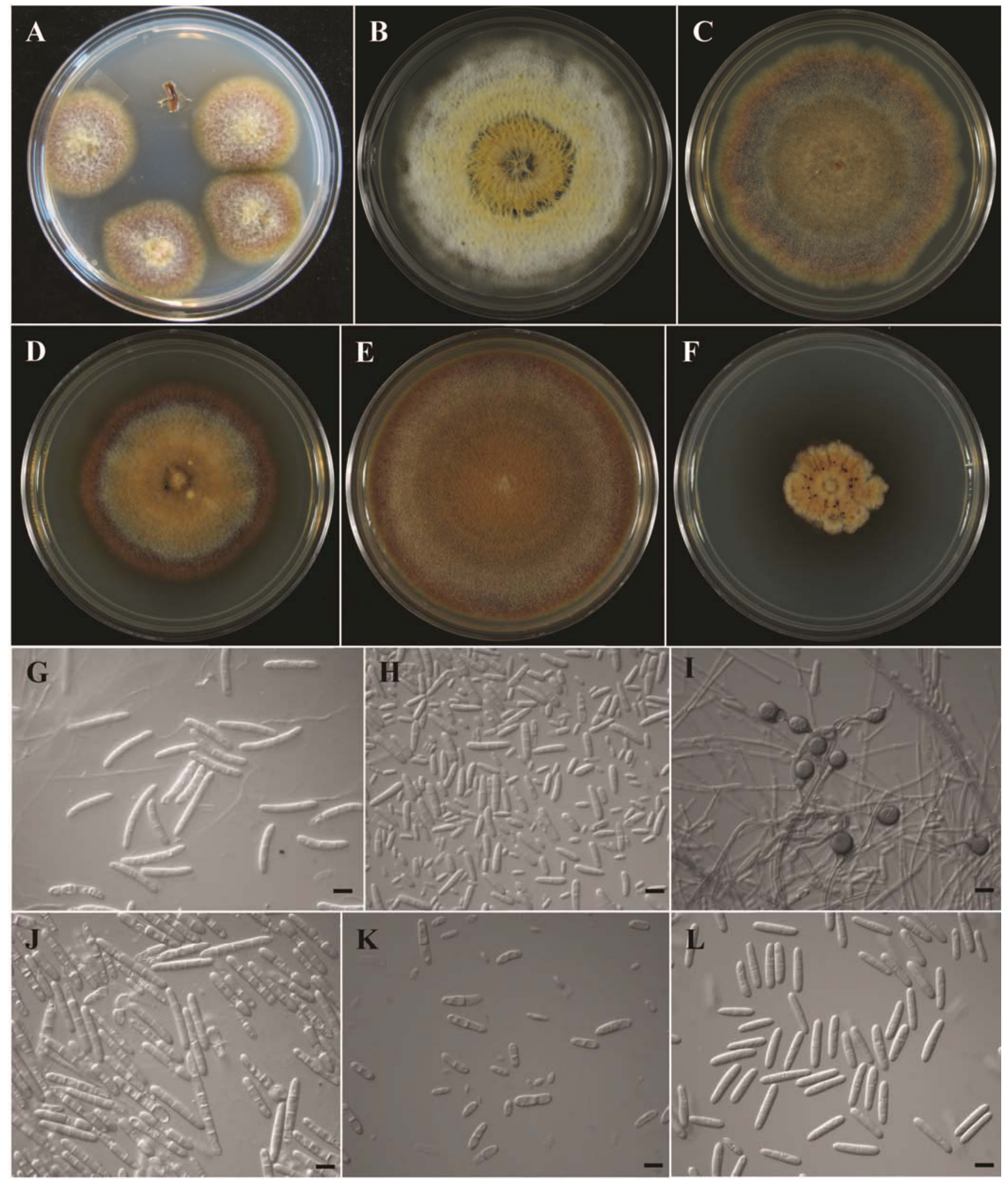

Fig. 2. Colony and conidia morphology of Cylindrocarpon/llyonectria species isolated from declining young vines in British Columbia. A, Cylindrocarpon/llyonectria developing from infected roots on PDA-tet. Colony (B) and conidia (G) morphology of Cylindrocarpon pauciseptatum PARC82. Colony (C), conidia (H) and chlamydospores (I) morphology of llyonectria liriodendri PARC60. Colony (D) and conidia (J) morphology of I. macrodidyma PARC345. Colony (E) and conidia (K) morphology of I. robusta PARC358. Colony (F) and conidia (L) morphology of $I$. torresensis PARC35. Bars $\mathrm{G}$ to $\mathrm{L}=10 \mu \mathrm{l}$. 
(Fig. 4O). Percent recovery from inoculated roots varied between $46.7 \%$ for I. torresensis isolate PARC35 and I. robusta isolate PARC391 and $78.3 \%$ for I. robusta isolate PARC358 (Fig. 4C). Fungi obtained from reisolation of both rootstock and roots were the same as the previously inoculated based on colony and conidia morphology. No Ilyonectria or Cylindrocarpon spp. were reisolated from the controls. The necrotic cross-sectional area measured at the base of the rootstock ranged from $46.8 \%$ for I. robusta

Table 4. Conidial dimensions of the different Cylindrocarpon and Ilyonectria species from British Columbia used in this study and comparison with ex-type specimens

\begin{tabular}{|c|c|c|c|c|c|c|c|c|}
\hline \multirow{2}{*}{\multicolumn{2}{|c|}{ Species/isolate ${ }^{b}$}} & \multirow[b]{2}{*}{ Septa $^{c}$} & \multicolumn{3}{|r|}{ Macroconidia $^{a}$} & \multicolumn{3}{|r|}{ Microconidia $^{\mathrm{a}}$} \\
\hline & & & $n$ & $\mathbf{L} / \mathbf{W}$ & Length $\times$ width $(\mu \mathrm{m})$ & $n$ & $\mathbf{L} / \mathbf{W}$ & Length $\times$ width $(\mu \mathrm{m})$ \\
\hline \multirow{8}{*}{ 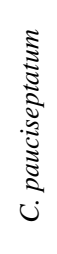 } & PARC82 & 0 & $\ldots$ & $\ldots$ & & 100 & 2.1 & $(5.1-) 6.2-6.3-6.4(-12.2) \times(2.8-) 4.0-4.1-4.2(-5.9)$ \\
\hline & & 1 & 20 & 6.4 & $(25.5-) 40.1-44-47.9(-56.2) \times(5.2-) 6.5-6.8-7.1(8.3)$ & $\ldots$ & $\ldots$ & $\ldots$ \\
\hline & & 2 & 10 & 7.2 & $(32.6-) 39.9-43.6-47.3(-50.6) \times(5.2-) 5.7-6.1-6.5(-7.1)$ & $\ldots$ & $\ldots$ & $\ldots$ \\
\hline & & 3 & 100 & 7 & $(35.4-) 46.2-47.3-48.5(-67.5) \times(5.2-) 6.7-6.8-6.9(-9.3)$ & $\ldots$ & $\ldots$ & $\ldots$ \\
\hline & CBS 120171 & 0 & 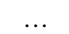 & $\ldots$ & & 100 & 1.6 & $(4.0-) 5.5-5.7-5.9(-10.4) \times(2.2-) 3.5-3.6-3.7(-5.2)$ \\
\hline & & 1 & 15 & 4.6 & $(31.5-) 35.7-37.8-39.8(-44.0) \times(6.6-) 7.7-8.3-8.9(-10.3)$ & $\ldots$ & $\ldots$ & $\ldots$ \\
\hline & & 2 & 15 & 4.8 & $(32.2-) 36.2-37.6-39.1(-41.7) \times(6.4-)-7.4-7.8-8.2(-8.9)$ & $\ldots$ & $\ldots$ & $\ldots$ \\
\hline & & 3 & 100 & 4.9 & $(31.7-) 39.2-39.8-40.4(-49.3) \times(6.2-) 8.0-8.2-8.4-(-10.1)$ & $\ldots$ & $\ldots$ & $\ldots$ \\
\hline \multirow{20}{*}{ 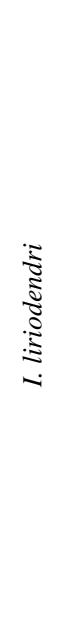 } & PARC60 & 0 & & $\cdots$ & & 100 & 2.3 & $(3.5-) 7.0-7.3-7.6(-10.7) \times(2.4-) 3.1-3.2-3.3(-4.3)$ \\
\hline & & 1 & 100 & 4.7 & $(14.6-) 21.1-21.7-22.4(-29.3) \times(3.6-) 4.5-4.6-4.8(-5.8)$ & 100 & 3.1 & $(8.1-) 10.9-11.3-11.6(-15.3) \times(2.6-) 3.5-3.6-7.1(-4.7)$ \\
\hline & & 2 & 35 & 5.3 & $(19.0-) 24.4-25.5-26.6(-31.9) \times(3.3-) 4.6-4.9-5.1(-6.4)$ & $\ldots$ & $\ldots$ & $\ldots$ \\
\hline & & 3 & 20 & 5 & $(20.4-) 25.2-25.4-25.6(-30.3) \times(4.3-4.9-5-5.1(-5.7)$ & $\ldots$ & $\ldots$ & \\
\hline & PARC340 & 0 & $\ldots$ & $\ldots$ & & 100 & 2.5 & $(4.3-) 7.1-7.5-7.8(-11.9) \times(2.0-) 2.9-3-3.1(-4.3)$ \\
\hline & & 1 & 100 & 5 & $(13.2-) 21.1-21.8-22.5(-28.0) \times(3.1-) 4.7-4.8-4.9(-6.9)$ & 60 & 3.4 & $(9.5-) 11.6-12.0-12.4(-15.3) \times(2.7-) 3.5-3.6-3.7(-4.6)$ \\
\hline & & 2 & 15 & 5.2 & $(23.6-) 26.2-26.6-27.0(-28.5) \times(4.3-) 5.0-5.1-5.2(-5.8)$ & $\ldots$ & $\ldots$ & $\ldots$ \\
\hline & & 3 & 10 & 6 & $(26.5-) 27.6-28.7-29.9(-31.1) \times(4.4-) 4.5-4.8-5.1(-5.7)$ & & & \\
\hline & PARC393 & 0 & $\ldots$ & $\ldots$ & & 100 & 2.5 & $(5.3-) 7.7-7.9-8.2(-11.6) \times(2.0-) 3.1-3.2-3.3(-4.6)$ \\
\hline & & 1 & 100 & 4.3 & $(14.5-) 19.0-19.5-20.0(-27.6-) \times(3.6-) 4.4-4.5-4.6(-6.2)$ & 100 & 3.1 & $(8.2-) 10.7-11.0-11.2(-13.7) \times(2.6-) 3.5-3.6-7.1(-5.8)$ \\
\hline & & 2 & 70 & 4.7 & $(19.0-) 22.7-23.3-23.8(-29.7) \times(4.3-) 4.8-4.9-5.0(-5.7)$ & $\ldots$ & $\ldots$ & $\ldots$ \\
\hline & & 3 & 50 & 4.8 & $(22.3-24.7-25.2-25.7(-28.6) \times(4.4-) 5.1-5.2-5.3(-6.3)$ & $\ldots$ & $\ldots$ & $\ldots$ \\
\hline & CBS 110.81 & 0 & $\ldots$ & $\ldots$ & $\ldots$ & 100 & 2.5 & $(4.0-) 6.9-7.2-7.5(-12.4) \times(2.0-) 2.8-2.9-3(-3.8)$ \\
\hline & & 1 & 90 & 5.1 & $(14.8-) 22.3-23.1-24(-32.1) \times(2.9-) 4.4-4.5-4.6(-5.9)$ & 100 & 3.4 & $(8.5-) 11.1-11.4-11.7(-15.7) \times(1.7-) 3.3-3.4-3.5(-4.9)$ \\
\hline & & 2 & 40 & 5.6 & $(17.4-25.2-26.6-28.1(-39.4) \times(2.9-) 4.6-4.8-5.0(-5.9)$ & $\ldots$ & $\ldots$ & $\ldots$ \\
\hline & & 3 & 100 & 6.1 & $(20.9-) 31.0-32.0-32.9(-42.3) \times(3.8-) 5.2-5.3-5.4(-6.8)$ & . & & \\
\hline & CBS 112595 & 0 & $\ldots$ & $\ldots$ & & 80 & 2.7 & $(3.3-) 7.4-7.8-8.1(-11.8) \times(1.5-) 2.8-2.9-3(-4.6)$ \\
\hline & & 1 & 100 & 5.2 & $(16.0-) 22.6-23.3-24.0(-30.9) \times(3.1-$ & 30 & 3.7 & $(7.1-) 10.8-11.4-12(-14.1) \times(2.1-) 2.9-3.1-3.3(-4.4)$ \\
\hline & & 2 & 100 & 5.6 & $(20.7-) 26.4-26.8-27.2(-31.9) \times(3.1-) 4.8-4.9-5.0(-6.4)$ & $\ldots$ & $\ldots$ & $\ldots$ \\
\hline & & 3 & 85 & 5.7 & $(23.8-) 28.5-28.9-29.3(-33.4) \times(3.9-) 5.0-5.1-5.2(-6.3)$ & $\ldots$ & $\ldots$ & $\ldots$ \\
\hline \multirow{14}{*}{ 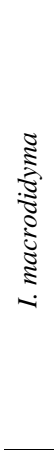 } & PARC345 & 0 & $\ldots$ & $\ldots$ & & 45 & 3.8 & $(12.6-) 19.7-19.8-19.9(-22.9) \times(3.3-) 5.3-5.6-5.9(-7.5)$ \\
\hline & & 1 & 65 & 5.9 & $(30.4-) 39.6-41.6-43.5(-62.4) \times(5.3-) 6.8-7.0-7.2(-8.8)$ & $\ldots$ & $\ldots$ & $\ldots$ \\
\hline & & 2 & 65 & 6.5 & $(35.0-) 47.9-49.5-51.0(-64.2) \times(5.9-) 7.4-7.6-7.8(-9.1)$ & $\ldots$ & $\ldots$ & $\ldots$ \\
\hline & & 3 & 100 & 7.2 & $(41.8-) 54.5-55.4-56.4(-69.9) \times(5.7-) 7.6-7.8-7.9(-9.9)$ & $\ldots$ & $\ldots$ & $\ldots$ \\
\hline & & 4 & 20 & 7.9 & $(52.2-) 59.1-61.8-64.4(-71.2) \times(6.6-) 7.5-7.8-8.1(-9.2)$ & $\ldots$ & $\ldots$ & $\ldots$ \\
\hline & & 5 & 10 & 10.1 & $(53.4-) 68.6-77.5-86.5(-94.3) \times(7.2-) 7.3-7.7-8.1(-9.0)$ & & & \\
\hline & PARC398 & 0 & $\ldots$ & $\ldots$ & & 100 & 3.5 & $(10.5-) 17.4-17.5-17.6(-23.0) \times(3.9-) 6.0-6.1-6.2(-8.3)$ \\
\hline & & 1 & 40 & 6.4 & $(37.4-) 48.5-50.2-51.9(-61.4) \times(6.2-) 7.7-7.9-8.2(-10.0)$ & $\ldots$ & $\ldots$ & $\ldots$ \\
\hline & & 2 & 20 & 6.2 & $(46.2-) 49.3-50.9-52.6(-59.4) \times(7.0-) 8.0-8.3-8.6(-9.5)$ & $\ldots$ & $\ldots$ & $\ldots$ \\
\hline & & 3 & 60 & 6.6 & $(44.5-) 51.7-52.7-53.7(-62.6) \times(6.6-) 7.9-8.0-8.2(-9.6)$ & $\ldots$ & $\ldots$ & $\ldots$ \\
\hline & & 4 & 10 & 8 & $(57.0) 58.0-61.1-64.2(-70.8) \times(7.2-) 7.4-7.7-8.0(-8.7)$ & $\ldots$ & $\ldots$ & $\ldots$ \\
\hline & CBS 112615 & 0 & $\ldots$ & $\ldots$ & & 100 & 2.2 & $(3.6-) 7.4-7.8-8.1(-12.3) \times(1.8-) 3.5-3.6-3.7(-5.2)$ \\
\hline & & 1 & 60 & 4 & $(12.9-) 17.5-18.6-19.7($ & 90 & 2.9 & $(8.8-) 11.6-12.0-12.3(-15.7) \times(2.9-) 4.0-4.1-4.3(-5.8)$ \\
\hline & & 2 & 20 & 5.7 & $(26.5-) 27.5-28.7-29.9(-31.2) \times(4.3-) 4.7-5.1-5.5(-6.2)$ & $\ldots$ & $\ldots$ & $\ldots$ \\
\hline \multirow{7}{*}{\begin{tabular}{l}
$\frac{\Xi}{5}$ \\
$\vdots$ \\
$\vdots$ \\
\hdashline \\
\hdashline
\end{tabular}} & PARC358 & 0 & ... & $\ldots$ & & 100 & 2.1 & $(3.7-) 7.1-7.3-7.6(-11.0) \times($ \\
\hline & & 1 & 100 & 4 & $(14.9-) 22.4-23.2-24.0(-31.0) \times(4.0-) 5.6-5.8-5.9(-9.4)$ & 50 & 3.1 & $(7.9-) 12.8-13.4-14.1(-18.3) \times(3.4-) 4.2-4$. \\
\hline & & 2 & 20 & 4.4 & $(14.9-) 24.2-26.8-29.4(-34.7) \times(5.2-) 5.9-6.2-6.4(-6.8)$ & $\ldots$ & $\ldots$ & $\ldots$ \\
\hline & & 3 & 10 & 5.5 & $(26.1-) 26.4-29.5-32.6(-33.6) \times(4.4-) 4.5-5.4-6.3(-7.1)$ & & & \\
\hline & CBS 773.83 & 0 & $\ldots$ & $\ldots$ & & 100 & 2.2 & $(3.3-) 6.0-6.2-6.4(-9.3) \times(1.3-) 2.9-3.0-3.1(-4.3)$ \\
\hline & & 1 & 65 & 2.6 & $(9.3-) 12.8-13.3-13.7(-19.3) \times(3.2-) 4.9-5.1-5.3(-7.2)$ & 100 & 2.5 & $(6.3-) 9.4-9.7-9.9(-12.0) \times(2.2-) 3.8-3.9-4.0(-5.6)$ \\
\hline & & 2 & 15 & 3.8 & $(18.0-) 19.9-21.1-22.2(-24.2) \times(4.5-) 5.3-5.6-6(-6.8)$ & $\ldots$ & $\ldots$ & $\ldots$ \\
\hline \multirow{10}{*}{ 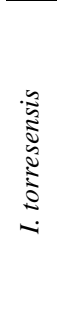 } & PARC14 & 0 & $\ldots$ & $\ldots$ & & 50 & 2.8 & $(7.6-) 8.8-11.0-13.3-(15.4) \times(3.1-) 3.6-4.0-4.4(-4.6)$ \\
\hline & & 1 & 100 & 4.7 & $(21.7-) 28.2-28.8-29.4(-35.2) \times(4.4-) 6.0-6.1-6.3(-7.7)$ & $\ldots$ & $\ldots$ & $\ldots$ \\
\hline & & 2 & 10 & 5.5 & $(28.1-) 30.8-33.0-35.1(-35.6) \times(5.2-) 5.6-6.0-6.3(-6.6)$ & $\ldots$ & $\ldots$ & $\ldots$ \\
\hline & PARC35 & 0 & $\ldots$ & $\ldots$ & & 35 & 3.4 & $(9.4-) 12.5-14.2-15.9(-17.9) \times(3.6-) 3.8-4.2-4.7(-5.3)$ \\
\hline & & 1 & 100 & 4.8 & $(22.4-) 28.3-28.8-29.2(-34.3) \times(4.0-) 5.9-6.1-6.2(-8.3)$ & $\ldots$ & $\ldots$ & $\ldots$ \\
\hline & & 2 & 10 & 5.3 & $(26.5-) 29.4-31.7-34(-35.3) \times(4.6-) 5.6-6.1-6.6(-6.8)$ & $\ldots$ & & \\
\hline & CBS $129086^{\mathrm{d}}$ & 0 & $\ldots$ & $\ldots$ & & 30 & 2.9 & $(9.0-) 11.8-12.3-12.7(-16.0) \times(3.5-) 4.2-4.3-4.4(-5.0)$ \\
\hline & & 1 & 30 & 4.9 & $(20.0-) 26.5-27.7-28.9(-43.0) \times(4.5-) 5.5-5.6-5.8(-7.0)$ & 30 & 3.6 & $(11.0-) 15.0-15.5-16.0(20.0) \times(3.5-) 4.3-4.4-4.5(-5.5)$ \\
\hline & & 2 & 30 & 5.2 & $(24.0-) 31.4-32.5-33.6(-44.0) \times(5.0-) 6.0-6.2-6.4(-8.0)$ & $\ldots$ & $\ldots$ & $\ldots$ \\
\hline & & 3 & 30 & 5.8 & $(30.0-) 38.3-39.4-40.6(-56.0) \times(5.0-) 6.7-6.8-7.0(-9.0)$ & $\ldots$ & $\ldots$ & $\ldots$ \\
\hline
\end{tabular}

\footnotetext{
${ }^{a} n$ : Total number of conidia measured. L/W: Length width ratio. Length $\times$ width: (minimum-)lower limit 95\% confidence interval-average-upper limit $95 \%$ confidence interval(-maximum).

${ }^{\mathrm{b}}$ Isolates in bold represent ex-type specimens.

${ }^{c}$ Number of septa observed in the different type of both macroconida and microconidia.

d Macroconidia and microconidia measurements taken from Cabral et al. (9).
} 
isolate PARC358 to $28.2 \%$ for I. torresensis isolate PARC14 (Fig. 4D). With the exception of these two isolates, the necrotic area did not differ among the isolates tested.

Grapevine vigor was reduced by some of the fungal treatments. Only vines inoculated with I. macrodidyma isolates PARC345 and
PARC340 showed significantly lower shoot weights (6.6 and $7.1 \mathrm{~g}$, respectively) than those from control plants (Fig. 4E). Root dry weights were lower and significantly different for plants inoculated with I. macrodidyma isolate PARC345 $(3.9 \mathrm{~g})$, I. robusta isolate PARC358 (6 g), I. liriodendri isolate PARC340 (6.3 g), and $C$.

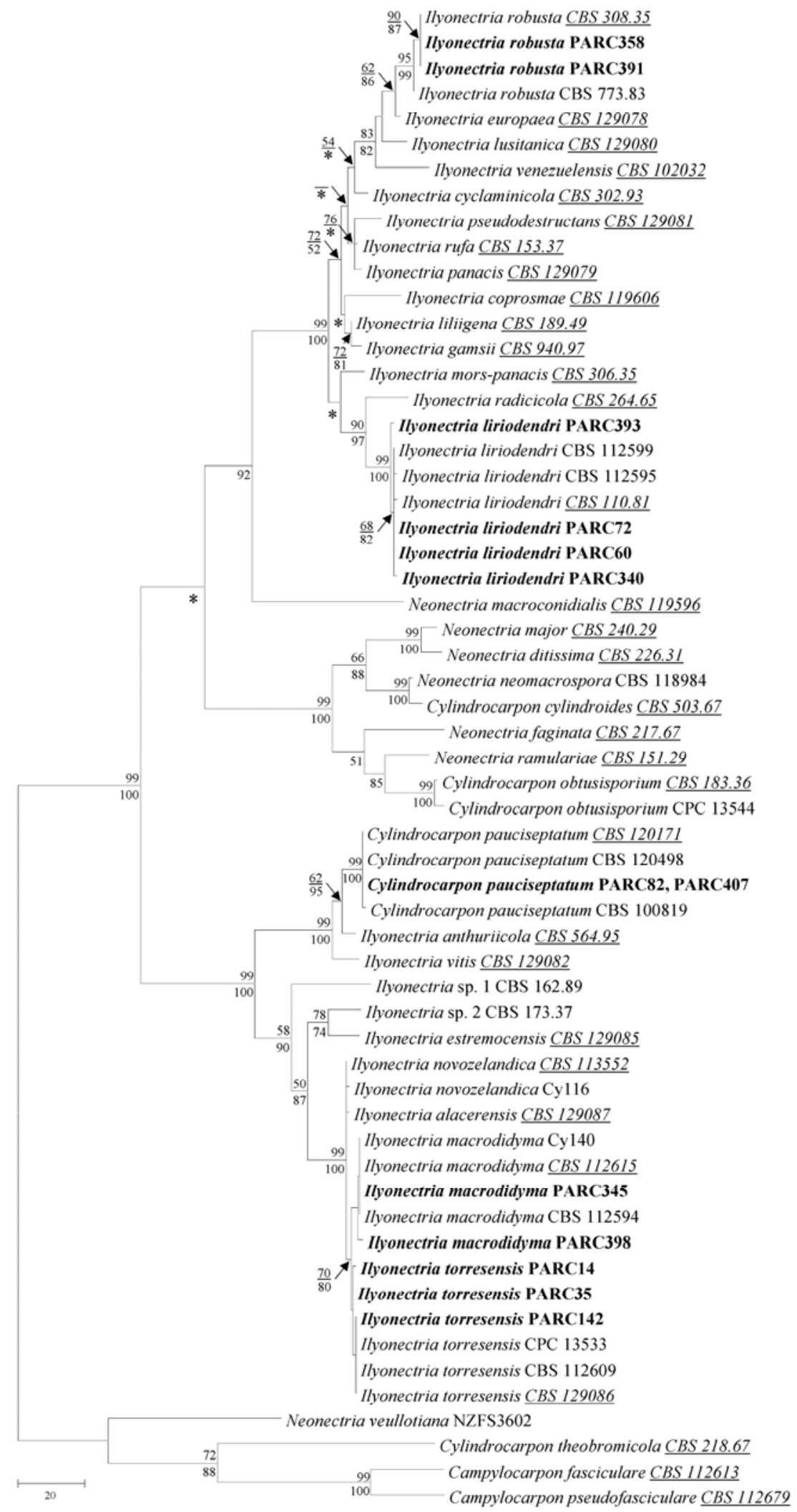

Fig. 3. One of 33 equally parsimonious trees resulting from a total of 958 positions in the final ITS, BT, and EF1- $\alpha$ combined dataset. Consistency index $(\mathrm{Cl})=0.541$, retention index $(\mathrm{RI})=0.881$, retention composite index $(\mathrm{RC})=0.519$. Isolates in bold represent Cylindrocarpon/llyonectria isolated from grapevines from British Columbia Isolates in italics and underline represent ex-type specimens. Bootstrap values with 1,000 replications are shown above branches for Maximum Parsimony (MP) (only bootstrap values higher than $50 \%$ are shown) and below the branches for Neighbor-Joining ( $\mathrm{NJ}$ ). Branches represented with an * were not present in the $\mathrm{NJ}$ tree. 
A
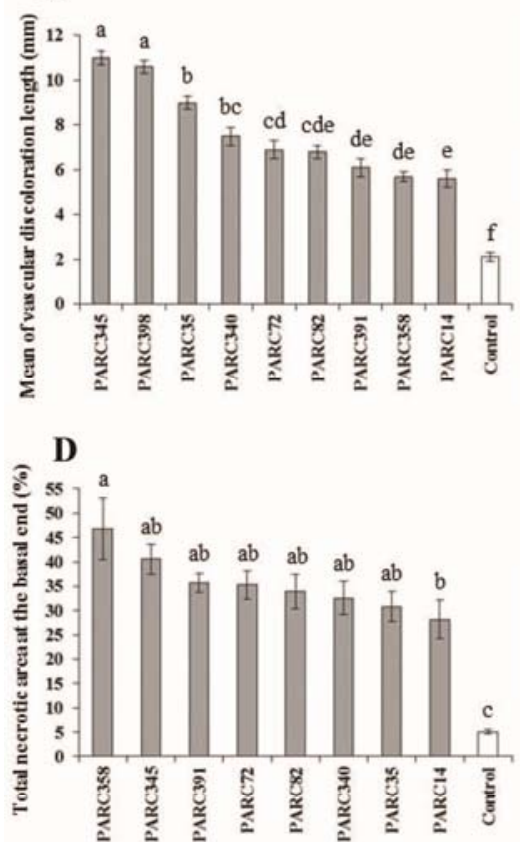

G

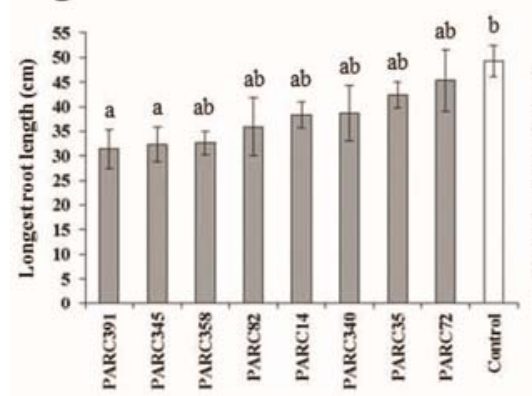

B
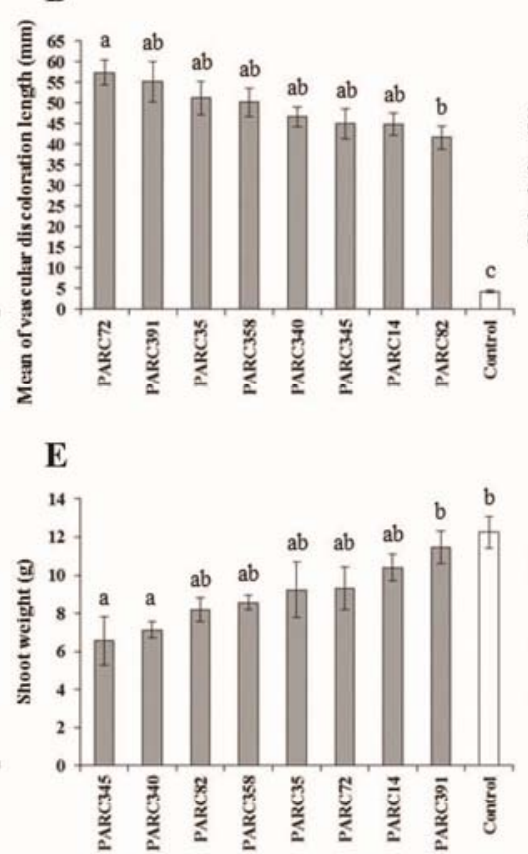

H

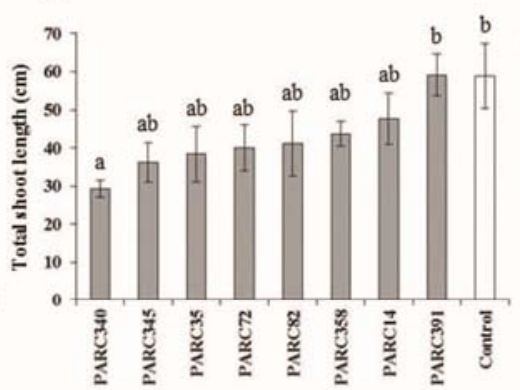

C

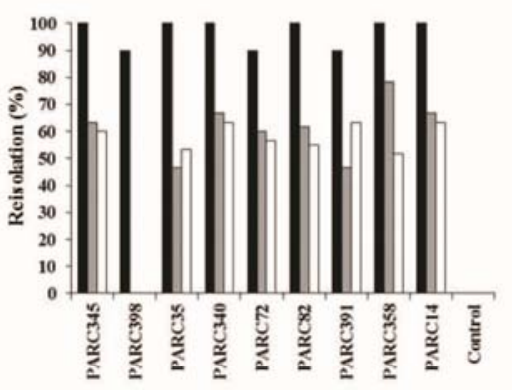

F

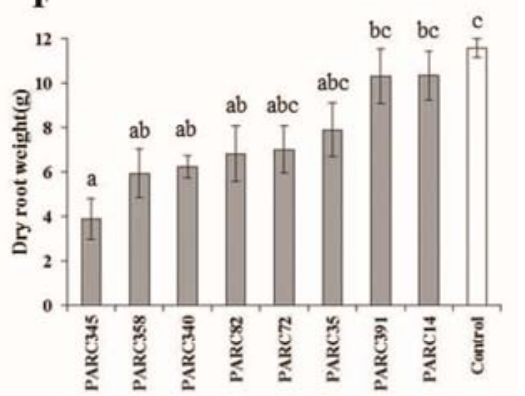

I

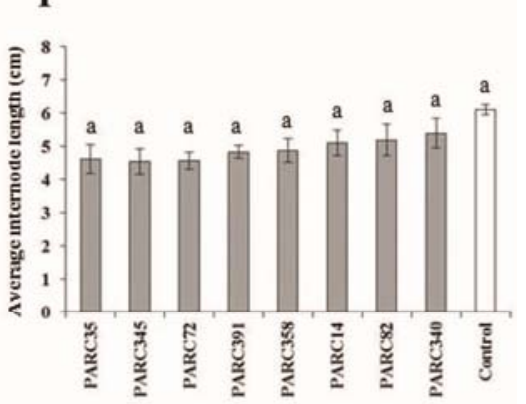

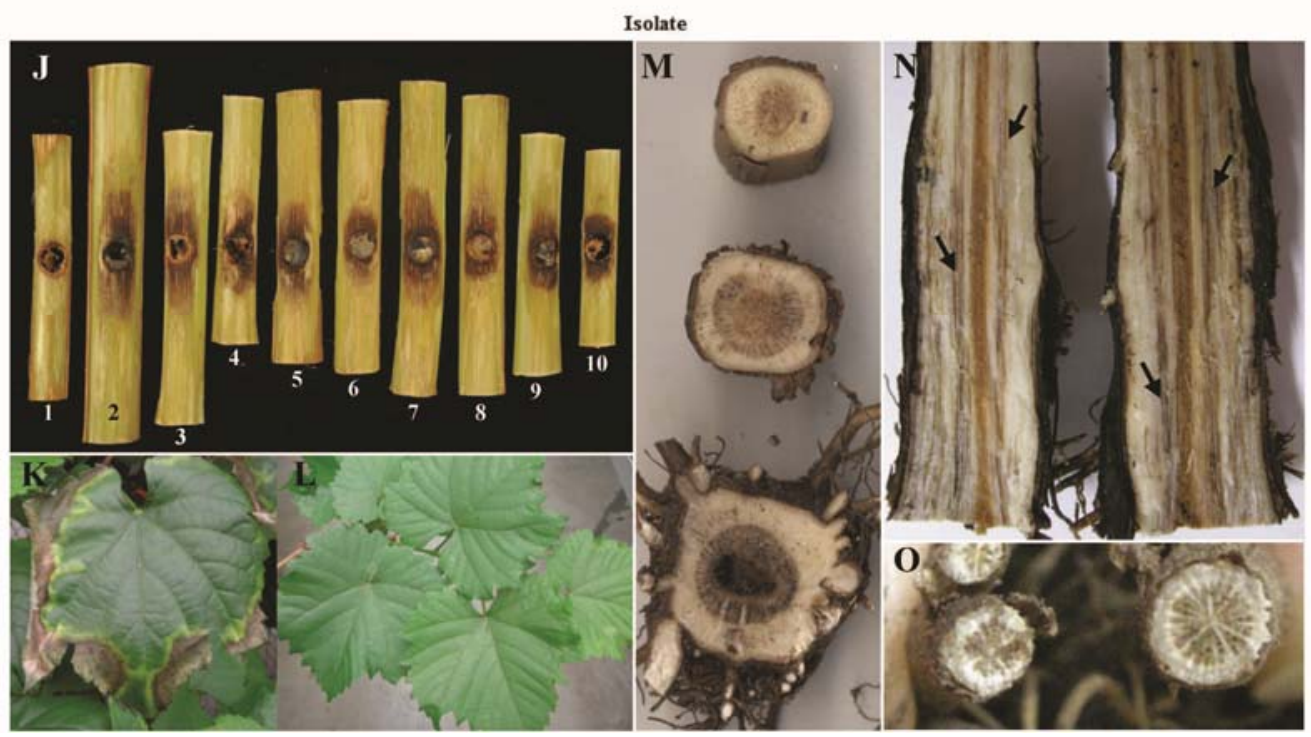

Fig. 4. Pathogenicity study of Cylindrocarpon/llyonectria species isolated from declining young vines in British Columbia. A, Mean lesion length caused by nine isolates in detached 'Chardonnay' dormant canes. B, Mean lesion length caused by eight isolates in grapevine rootstock cv. 3309C measured from the basal end. C, Percentage of recovery of Cylindrocarpon/llyonectria species from detached 'Chardonnay' green shoots (- $\mathbf{-}$ ), vascular discoloration in the rootstock developing from the basal end ( $\square$ ) and necrotic roots ( $\square$ ). D to I, Effect of eight Cylindrocarpon/llyonectria species from BC in vine growth of grapevine 'Baco Noir' grafted on rootstock 3309C recorded as total necrotic area (\%) measured $5 \mathrm{~mm}$ above the basal end of the rootstock (D), total shoot weight $(\mathbf{E})$, total dry root weight (F), length of the longest root $(\mathrm{cm})(\mathbf{G})$, total shoot length $(\mathrm{cm})(\mathrm{H})$, and average internode length $(\mathrm{cm})(\mathrm{I}) . \mathrm{J}$ to $\mathrm{O}$, Reproduction of symptoms observed from the pathogenicity tests. J, Vascular necrosis caused on detached 'Chardonnay' green shoots by control (1), I. macrodidyma PARC345 (2) and PARC398 (3), I. liriodendri PARC72 (4), PARC340 (5), C. pauciseptatum PARC82 (6), I. torresensis PARC35 (7), PARC14 (8), I. robusta PARC391 (9) and PARC358 (10). K, Leaf symptoms resembling water stress observed in inoculated potted plants. L, No symptoms were observed in leaves of control plants. M, Vascular necrosis observed in inoculated plants $5 \mathrm{~mm}$ above the basal end (below), $3 \mathrm{~cm}$ above the basal end (middle), and $7 \mathrm{~cm}$ above the basal end (top). $\mathbf{N}$, Vascular discoloration marked by black arrows observed to develop acropetally from the basal end of the trunk in inoculated potted plants. 0, Root necrosis observed in inoculated potted vines. 
pauciseptatum isolate PARC82 (6.8 g), than for control plants $(11.6 \mathrm{~g})$ (Fig. 4F). Length of the longest root ranged widely from $31.4 \mathrm{~cm}$ on average for I. robusta isolate PARC391 to $45.3 \mathrm{~cm}$ for I. liriodendri isolate PARC72, but there were no significant differences among fungal isolates. Only root lengths of isolates PARC391 and PARC345 were significantly shorter than watertreated control plants (Fig. 4G). Inoculated plants had between one and 1.8 shoots on average, whereas control plants averaged 2.4 shoots. Total shoot length ranged widely, and only for I. liriodendri isolate PARC340 was total shoot length significantly lower than for control plants (Fig. 4H). Average internode length was not influenced by the fungal inoculants (Fig. 4I).

\section{Discussion}

This study represents the first attempt to elucidate the incidence of black foot disease of grapevines and subsequently to identify the fungal species associated with this syndrome in BC. Morphological studies along with multi-gene sequence analyses revealed the identity of five species associated with black foot disease, including $C$. pauciseptatum, I. liriodendri, I. macrodidyma, I. robusta, and I. torresensis, which are reported for the first time to occur on grapevines in BC. Among these species, I. liriodendri and I. macrodidyma were the most prevalent black foot pathogens isolated from both necrotic roots and rootstocks in $\mathrm{BC}$. This is not surprising because both species are known to be the main fungi associated with black foot disease of grapevines elsewhere, and the abundance of either or both species has been similarly found in vineyards in Australia (49), California (32,34), Chile (6), Iran (28), New Zealand (22), Portugal $(8,10)$, eastern Canada (31), Spain (5), South Africa (22,23), and Uruguay (1). This study describes for the first time the occurrence in North America of $C$. pauciseptatum, a recently described Cylindrocarpon species that to date has been reported to occur in New Zealand (39), Slovenia (39), South Africa (44), Spain (26), and Uruguay (1). I. robusta and I. torresensis were the least prevalent black foot fungal species isolated from declining young vines in $\mathrm{BC}$, and whereas the former had until our finding not been found in a country other than Portugal (8), the latter has a wide geographical distribution that includes Australia, California, New Zealand, the Ontario Province in Canada, Portugal, South Africa, and Spain (10).

Black foot and Petri disease, the latter primarily caused by Phaeomoniella chlamydospora (W. Gams, Crous, M.J. Wingf. \& Mugnai) Crous \& W. Gams and Togninia minima (Tul. \& C. Tul.) Berl. (anamorph: Phaeoacremonium aleophilum W. Gams, Crous, M.J. Wingf. \& Mugnai), have been historically considered two separate grapevine trunk diseases responsible for the decline of young vines $(16,21)$. However, it is currently well-accepted that vascular and foliar symptomatology associated with black foot resembles that caused by Petri disease, and thus, disease diagnosis of individual maladies is extremely difficult based solely on field observations (16). Furthermore, Ilyonectria/Cylindrocarpon spp. have been broadly shown to be isolated along with Petri disease pathogens from the same infected vine $(13,16,35)$. Therefore, both diseases have been recently considered to constitute the young vine decline (YVD) complex (16). In this study, YVD symptoms were recorded in 68 of 90 vineyards surveyed. However, black foot disease from symptomatic vines in the field could only be confirmed when isolation and identification of the fungal pathogens from the vascular necrotic tissue was conducted. Additionally, results from this study revealed that the number of samples from which Ilyonectria/Cylindrocarpon spp. were the sole pathogen isolated were almost identical to those from which black foot fungi were found along with Petri disease or other grapevine trunk pathogens. Accordingly, although black foot can be considered as the sole cause of YVD in BC, results from this study further support black foot as part of the YVD disease complex (16). Ilyonectria/Cylindrocarpon spp. are soilborne pathogens, and thus, black foot diagnosis in the field has been historically based on the observation of sunken necrotic roots from symptomatic vines $(21,23)$. However, recent studies have shown Petri disease patho- gens to be also isolated from grapevine roots and soil $(20,36)$. Interestingly, the majority of Ilyonectria/Cylindrocarpon isolates obtained in this study were not isolated from infected roots but from the base of the trunk where Petri disease pathogens also commonly occur. Based on isolation data, incidence of black foot fungal pathogens observed in the current study was higher than that recently reported by Petit et al. (31) in grape-growing regions of northeastern United States and southeastern Canada where black foot fungi were identified in $28.6 \%$ of vineyards surveyed (4 out of 14 ) and in $13.3 \%$ of samples collected (12 out of 90).

Colony and conidia morphology have been extensively used to identify Cylindrocarpon/Ilyonectria spp. associated with black foot disease of grapevines $(5,22,23,32,39)$. However, while phenotypic characters are valuable for the identification of some species $(11,22,39)$, they are insufficient for distinguishing others. Furthermore, identification of Cylindrocarpon/Ilyonectria spp. based only on morphology has become difficult due to the broad number of species identified, including cryptic species from grapevines and other hosts. Although we were able to separate all isolates into five morphological groups, identification of Cylindrocarpon/Ilyonectria isolates from $\mathrm{BC}$ to species was challenging on the sole basis of phenotypical characteristics even with access to several ex-type specimens for comparison. Therefore, molecular analyses were required to accurately identify to species the Cylindrocarpon/ Ilyonectria isolates from BC. Phylogenetic analyses of individual ITS, BT, and EF1- $\alpha$ datasets allowed us to precisely identify and separate C. pauciseptatum, I. liriodendri, and I. robusta isolates from $\mathrm{BC}$, which fell into well-supported clades along with their respective ex-type specimens (individual trees not shown). However, individual phylogenies as well as the combined ITS+BT and ITS $+\mathrm{EF} 1-\alpha$ analyses were not able to differentiate between $I$. torresensis and I. macrodidyma isolates from $\mathrm{BC}$, including the extypes. Differentiation between I. torresensis and I. macrodidyma was only possible when BT $+\mathrm{EF} 1-\alpha$ or ITS $+\mathrm{BT}+\mathrm{EF} 1-\alpha$ combined datasets were analyzed. High genetic diversity among I. liriodendri and I. macrodidyma isolates has been detected since phylogenetic analyses were included in Cylindrocarpon studies $(1,22,23,41)$. However, multi-gene sequence analyses by using the BT, histone $H 3$, and EF1- $\alpha$ have recently resolved part of this genetic diversity, revealing 12 and six new taxa within, respectively, the I. liriodendri and I. macrodidyma species complex from different hosts, including $I$. torresensis within the latter species complex $(8,10)$. Interestingly, based on these recent findings, I. torresensis was already isolated from roots and stems of grapevines in Ontario, Canada, in 1998 but was incorrectly identified as Cylindrocarpon destructans var. destructans based solely on phenotypic characters (40).

This study revealed that the grapevine rootstock 3309 Couderc $(=3309$ C, Vitis riparia $\times$ Vitis rupestris $)$, which is the most widely planted rootstock cultivar in BC, is highly susceptible to infection by several Cylindrocarpon/Ilyonectria spp. The rootstock SO4, the second most widely planted in $\mathrm{BC}$, has been shown in previous studies to be among the most susceptible to infection by I. liriodendri and I. macrodidyma in California (30) and in Spain (4), respectively. Petit (30) showed AXR1 to be among the least susceptible rootstocks tested, and Riparia, 039-16, and Freedom to show no susceptibility to black foot disease. Consequently, and due to the extensive number of rootstocks planted in $\mathrm{BC}$ vineyards, a larger scale susceptibility trial, including the two most prevalent grapevine rootstocks and self-rooted cultivars of $V$. vinifera, is needed to provide $\mathrm{BC}$ growers with further information for selecting rootstocks for new plantings. Pathogenicity of all five Cylindrocarpon/Ilyonectria spp. found on declining young vines in $\mathrm{BC}$ has been characterized in previous studies conducted in different grape-growing regions $(9,22,32)$. A recent pathogenicity study involving 60 different isolates from 14 Cylindrocarpon/ Ilyonectria spp. concluded that root lesions, vascular discoloration, and necrosis in the basal end of the vine trunks were symptoms difficult to quantify (9). On the other hand, black foot pathogenicity studies conducted in California (32) and Spain (5) showed 
root rot severity as a quantifiable parameter. We found that although root lesions were observed in all inoculated plants, lesion severity is a challenging factor to precisely quantify. However, length of vascular discoloration measured from the base of the rootstock, and necrotic area measured cross-sectionally at the stem base, were used successfully to quantify disease symptoms in the current study. Among the five species identified in this study, $I$. macrodidyma was the most virulent on Chardonnay canes. Overall, I. macrodidyma isolate PARC345 and I. liriodendri PARC340 caused the most severe reductions in total dry root weight (66 and $47 \%$ reduction, respectively), total shoot length (38.4 and 49.7\%), and shoot weight (50 and 42\%) compared with the control, which agrees with results obtained previously $(9,32)$. Short shoot internodes have been described as a characteristic symptom of YVD. Interestingly, no effects of infection on internode length were detected in this study. Short internode symptoms are commonly observed in the field 2 to 3 years after infected vines are planted, and thus a long-term pathogenicity trial may be required to reproduce this type of symptom.

Cylindrocarpon/Ilyonectria spp. are soilborne pathogens that can remain in the soil after an infected plant or the entire crop has been removed (44). Other than grapevines, several other economically important perennial crops, including apple (Malus domestica L.) (44), ginseng (Panax quinquefolius L.) (41), olive (Olea europaea L.) (46), and peach (Prunus persica L.) (50) were shown to be susceptible to Cylindrocarpon/Ilyonectria infection, which causes significant root rot and consequent decline. Furthermore, a recent study revealed Cylindrocarpon/Ilyonectria isolates from nongrape hosts to be as virulent to grapevines as those obtained from grapes (9). In the current study, two of the 32 vineyards in which Cylindrocarpon/Ilyonectria spp. were isolated from declining vines were previously ginseng plantations. However, further studies are required to confirm that the young vines were infected by inoculum already established in the soil. Cylindrocarpon/ Ilyonectria spp. have long been known to be part of the pathogen complex implicated in apple replant disease, which is a devastating problem in apple characterized by the stunted growth in young trees planted in soils previously cultivated to apple (27). In a study of replant disease in BC, Utkhede and Thomas (47) concluded that grapes should not be planted after apples without soil treatment to reduce inoculum. None of the vineyards from which black foot pathogens were isolated in the current study were established in pulled out apple orchards. However, removal of apple trees for vineyard establishment is a common practice in $\mathrm{BC}$. This information may be useful to growers judging the risk of planting grapes following apples or other crops susceptible to infection caused by Cylindrocarpon/Ilyonectria spp., and in assessing whether to conduct costly tests for pathogens and treat soils prior to planting.

In the current study, all but two vineyards containing Cylindrocarpon/Ilyonectria spp. were established on noncultivated lands or at sites previously planted with grapevines. The black foot inoculum may have pre-existed in the soil previously planted with grapevines, but it is improbable that high inoculum levels of Cylindrocarpon/Ilyonectria spp. were present in the noncultivated soils. Studies conducted during the past decade have thoroughly documented that grapevine transplants can become infected by black foot pathogens during propagation at nurseries before establishment in vineyards $(13,16,22)$. However, practices can be implemented at nurseries to control black foot infections, including hot water treatments, fungicide baths, and soil amendments with biological agents such as Trichoderma spp. and/or mycorrhizal fungi $(3,16,21,33)$. Although grapevines have been planted in $\mathrm{BC}$ for more than 100 years, the industry has undergone a conversion to $V$. vinifera varieties and planted more than 10,000 acres of vineyards in the last 25 years using transplants produced in different countries. Consequently, it is recommended that the transplants be acquired from registered nurseries that produce disease-free plants and practice strategies to avoid and control black foot contamination. Further studies to determine the quality and infection status of the planting material being currently used in $\mathrm{BC}$ should be encouraged.

\section{Acknowledgments}

This study was possible thanks to a research grant awarded by the British Columbia Wine Grape Council and with matching funds provided by Agriculture and Agri-Food Canada's Developing Innovative Agri-Products (DIAP) program. Special thanks to M. Sheepwash (Vancouver Island University, Nanaimo) and J. Dick (University of British Columbia, Vancouver) for their valuable technical assistance in the study and to M. M. Weis (Pacific Agri-Food Research Centre, Summerland, BC) for providing assistance with microscope and digital imaging.

\section{Literature Cited}

1. Abreo, E., Martinez, S., Bettucci, L., and Lupo, S. 2010. Morphological and molecular characterisation of Campylocarpon and Cylindrocarpon spp. associated with black foot disease of grapevines in Uruguay. Australas. Plant Pathol. 39:446-452.

2. Agustí-Brisach, C., Alaniz, S., Gramaje, D., Pérez-Sierra, A., Armengol, J., Landeras, E., and Izquierdo, P. M. 2012. First report of Cylindrocladiella parva and C. peruviana associated with black-foot disease of grapevine in Spain. Plant Dis. 96:1381.

3. Alániz, S., Abad-Campos, P., García-Jiménez, J., and Armengol, J. 2011. Evaluation of fungicides to control Cylindrocarpon liriodendri and Cylindrocarpon macrodidymum in vitro, and their effect during the rooting phase in the grapevine propagation process. Crop Prot. 30:489-494.

4. Alániz, S., García-Jiménez, J., Abad-Campos, P., and Armengol, J. 2010. Susceptibility of grapevine rootstocks to Cylindrocarpon liriodendri and $C$. macrodidymum. Sci. Hortic. 125:305-308.

5. Alániz, S., León, M., Vicent, A., García-Jiménez, J., Abad-Campos, P., and Armengol, J. 2007. Characterization of Cylindrocarpon species associated with black foot disease of grapevines in Spain. Plant Dis. 91:1187-1193.

6. Auger, J., Esterio, M., and Pérez, I. 2007. First report of black foot disease of grapevine caused by Cylindrocarpon macrodidymum in Chile. Plant Dis. 91:470.

7. Booth, C. 1966. The genus Cylindrocarpon. Mycol. Pap. 104:1-56.

8. Cabral, A., Groenewald, Z. J., Rego, C., Oliveira, H., and Crous, P. W. 2012. Cylindrocarpon root rot: Multi-gene analysis reveals novel species within the Ilyonectria radicicola species complex. Mycol. Prog. 11:655-688.

9. Cabral, A., Rego, C., Crous, P. W., and Oliveira, H. 2012. Virulence and cross-infection potential of Ilyonectria spp. to grapevine. Phytopathol. Mediterr. 51:340-354

10. Cabral, A., Rego, C., Nascimento, T., Oliveira, H., Groenewald, Z., and Crous, P. W. 2012. Multi-gene analysis and morphology reveal novel Ilyonectria species associated with black foot disease of grapevines. Fungal Biol. 116:62-80.

11. Chaverri, P., Salgado, C., Hirooka, Y., Rossman, A. Y., and Samuels, G. J. 2011. Delimitation of Neonectria and Cylindrocarpon (Nectriaceae, Hypocreales, Ascomycota) and related genera with Cylindrocarpon-like anamorphs. Stud. Mycol. 68:57-78.

12. Farr, D. F., and Rossman, A. Y. Fungal Databases, Systematic Mycology and Microbiology Laboratory, ARS, USDA. Retrieved May 10, 2013, from http://nt.ars-grin.gov/fungaldatabases/fungushost/fungushost.cfm

13. Gimenez-Jaime, A., Aroca, A., Raposo, R., Garcia-Jimenez, J., and Armengol, J. 2006. Occurrence of fungal pathogens associated with grapevine nurseries in Spain. J. Phytopathol. 154:598-602.

14. Ginns, J. H. 1986. Compendium of plant diseases and decay fungi in Canada 1960-1980. Research Branch Agriculture Canada Publ. 1813.

15. Glass, N. L., and Donaldson, G. 1995. Development of primer sets designed for use with PCR to amplify conserved genes from filamentous Ascomycetes. Appl. Environ. Microbiol. 61:1323-1330.

16. Gramaje, D., and Armengol, J. 2011. Fungal trunk pathogens in the grapevine propagation process: Potential inoculum sources, detection, identification, and management strategies. Plant Dis. 95:1040-1055.

17. Grasso, S. 1984. Infezioni di Fusarium oxysporum e di Cylindrocarpon destructans associate a una moria di giovani piante di vite in Sicilia. Inform. Fitopatol. 1:59-63.

18. Grasso, S., and Magnano di San Lio, G. 1975. Infezioni di Cylindrocarpon obtusisporium su piante di vite in Sicilia. Vitis 14:36-39.

19. Hall, T. A. 1999. BioEdit: A user-friendly biological sequence alignment editor and analysis program for Windows 95/98/NT. Nucleic Acid S. 41:9598.

20. Halleen, F., Crous, P. W., and Petrini, O. 2003. Fungi associated with healthy grapevine cuttings in nurseries, with special reference to pathogens involved in the decline of young vines. Australas. Plant Path. 32:47-52.

21. Halleen, F., Fourie, P. H., and Crous, W. C. 2006. A review of black foot disease of grapevines. Phytopathol. Mediterr. 45:S55-S67.

22. Halleen, F., Schroers, H. J., Groenewald, J. Z., and Crous, P. W. 2004 Novel species of Cylindrocarpon (Neonectria) and Campylocarpon gen nov. associated with black foot disease of grapevines (Vitis spp.). Stud. Mycol. 50:431-455.

23. Halleen, F., Schroers, H. J., Groenewald, J. Z., Rego, C., Oliveira, H., and Crous, P. W. 2006. Neonectria liriodendri sp. nov., the main causal agent of 
black foot disease of grapevines. Stud. Mycol. 55:227-234.

24. Jones, E. E., Brown, D. S., Bleach, C. M., Pathrose, B., Barclay, C., Jaspers, M. V., and Ridgway, H. J. 2012. First report of Cylindrocladiella parva as a grapevine pathogen in New Zealand. Plant Dis. 96:144.

25. Maluta, D. R., and Larignon, P. 1991. Pied-noir: Mieux vaut prevenir. Viti 11:71-72.

26. Martin, M. T., Martin, L., Cuesta, M. J., and Garcia-Benavides, P. 2011. First report of Cylindrocarpon pauciseptatum associated with grapevine decline from Castilla y Leon, Spain. Plant Dis. 95:361.

27. Mazzola, M., and Manici, M. 2012. Apple replant disease: Role of microbial ecology in cause and control. Annu. Rev. Phytopathol. 50:45-65.

28. Mohammadi, H., Alániz, S., Banihashemi, Z., and Armengol, J. 2009. Characterization of Cylindrocarpon liriodendri associated with black foot disease of grapevine in Iran. J. Phytopathol. 157:642-645.

29. O’Donnell, K., Kistler, H. C., Cigelnik, E., and Ploetz, R. C. 1998. Multiple evolutionary origins of the fungus causing Panama disease of banana: Concordant evidence from nuclear and mitochondrial gene genealogies. Proc. Nat. Acad. Sci. 95:2044-2049.

30. Petit, E. 2005. Characterization and control of black foot disease of grapevine in California. Ph.D. diss. University of California, Davis.

31. Petit, E., Barriault, E., Baumgartner, K., Wilcox, W. F., and Rolshausen, P. E. 2011. Cylindrocarpon species associated with black-foot of grapevines in northeastern United States and southeastern Canada. Am. J. Enol. Vitic. 62:177-183.

32. Petit, E., and Gubler, W. D. 2005. Characterization of Cylindrocarpon species, the cause of black foot disease of grapevines in California. Plant Dis. 89:1051-1059.

33. Petit, E., and Gubler, W. D. 2006. Influence of Glomus intraradices on black foot disease caused by Cylindrocarpon macrodidymum on Vitis rupestris under controlled conditions. Plant Dis. 90:1481-1484.

34. Petit, E., and Gubler, W. D. 2007. First report of Cylindrocarpon liriodendri causing black foot disease of grapevines in California. Plant Dis. 91:1060.

35. Rego, C., Oliveira, H., Carvalho, A., and Phillips, A. J. L. 2000. Involvement of Phaeoacremonium spp. and Cylindrocarpon destructans with grapevine decline in Portugal. Phytopathol. Mediterr. 39:76-79.

36. Rooney-Latham, S., Eskalen, A., and Gubler, W. D. 2001. Recovery of Phaeomoniella chlamydospora and Phaeoacremonium inflatipes from soil and grapevine tissue. Phytopathol. Mediterr. 40:S351-S356.

37. Scheck, H. J., Vasquez, S. J., Gubler, W. D., and Fogle, D. 1998. First report of black-foot disease, caused by Cylindrocarpon obtusisporium, of grapevine in California. Plant Dis. 82:448.

38. Schindelin, J., Arganda-Carreras, I., Frise, E., Kaynig, V., Longair, M., Pietzsch, T., Preibisch, S., Rueden, C., Saalfeld, S., Schmid, B., Tinevez, J.-
Y., White, D. J., Hartenstein, V., Eliceiri, K., Tomancak, P., and Cardona, A. 2012. Fiji: An open-source platform for biological-image analysis. Nat. Methods 9:676-682.

39. Schroers, H.-J., Žerjav, M., Munda, A., Halleen, F., and Crous, P. W. 2008. Cylindrocarpon pauciseptatum sp. nov., with notes on Cylindrocarpon species with wide, predominantly 3-septa macroconidia. Mycol. Res. 112:8292.

40. Seifert, K. A., and Axelrood, P. E. 1998. Cylindrocarpon destructans var. destructans. Can. J. Plant Pathol. 20:115-117.

41. Seifert, K. A., McMullen, C. R., Yee, D., Reeleder, R. D., and Dobinson, K. F. 2003. Molecular differentiation and detection of ginseng-adapted isolates of the root rot fungus Cylindrocarpon destructans. Phytopathology 93:1533-1542.

42. Statistics Canada. Fruit and Vegetable Production 2011. Catalogue no 22003-XWE, vol. 80, no. 2. Online publication retrieved from http://www. statcan.gc.ca/pub/22-003-x/22-003-x2011002-eng.pdf

43. Tamura, K., Peterson, D., Peterson, N., Stecher, G., Nei, M., and Kumar, S 2011. MEGA5: Molecular Evolutionary Genetics Analysis using Maximum Likelihood, Evolutionary Distance, and Maximum Parsimony Methods. Mol. Biol. Evol. 28:2731-2739.

44. Tewoldemedhin, Y. T., Mazzola, M., Mostert, L., and McLeod, A. 2011. Cylindrocarpon species associated with apple tree roots in South Africa and their quantification using real-time PCR. Eur. J. Plant. Pathol. 129:637-651.

45. Úrbez-Torres, J. R., Adams, P., Kamas, J., and Gubler, W. D. 2009. Identification, incidence, and pathogenicity of fungal species associated with grapevine dieback in Texas. Am. J. Enol. Vitic. 60:497-507.

46. Úrbez-Torres, J. R., Peduto, F., and Gubler, W. D. 2012. First report of Ilyonectria macrodidyma causing root rot of olive trees (Olea europaea) in California. Plant Dis. 96:1378.

47. Utkhede, R. S., and Thomas, S. C. 1988. Determining the occurrence of replant disease in British Columbia orchard and vineyard soils by pasteurization. Can. Plant Dis. Surv. 68:149-151.

48. White, T. J., Bruns, T., Lee, S., and Taylor, J. 1990. Amplification and direct sequencing of fungal ribosomal RNA genes for phylogenetics. Pages 315322 in: PCR Protocols, A Guide to Methods and Applications. M. A. Innis, D. H. Gelfand, J. J. Sninsky, and T. J. White, eds. Academic Press, San Diego, CA.

49. Whitelaw-Weckert, M. A., Nair, N. G., Lamont, R., Alonso, M., Priest, M. J., and Huang, R. 2007. Root infection of Vitis vinifera by Cylindrocarpon liriodendri in Australia. Australas. Plant Pathol. 36:403-406.

50. Yaseen, T., Ahmed, Y., D’Onghia, A. M., and Digiaro, M. 2012. First report of Cylindrocarpon pauciseptatum associated with root rot and decline of peach in southern Italy (Apulia region). Plant Dis. 96:764. 